\title{
Steepest Ascent Tariff Reforms
}

\author{
Raimondos-Møller, Pascalis; Woodland, Alan D.
}

Document Version

Final published version

Publication date:

2006

\section{License \\ CC BY-NC-ND}

Citation for published version (APA):

Raimondos-Møller, P., \& Woodland, A. D. (2006). Steepest Ascent Tariff Reforms.

Link to publication in CBS Research Portal

\section{General rights}

Copyright and moral rights for the publications made accessible in the public portal are retained by the authors and/or other copyright owners and it is a condition of accessing publications that users recognise and abide by the legal requirements associated with these rights.

Take down policy

If you believe that this document breaches copyright please contact us (research.lib@cbs.dk) providing details, and we will remove access to the work immediately and investigate your claim. 


\title{
Department of Economics
}

Copenhagen Business School

\section{Working paper 4-2006}

\section{STEEPEST ASCENT TARIFF REFORMS}

\author{
Pascalis Raimondos-Møller Alan D. Woodland
}




\title{
Steepest Ascent Tariff Reforms
}

\author{
By Pascalis Raimondos-Møller and Alan D. Woodland \\ June 23, 2006
}

\begin{abstract}
This paper introduces the concept of a steepest ascent tariff reform for a small open economy. By construction, it is locally optimal in that it yields the highest gain in utility of any feasible tariff reform vector of the same length. Accordingly, it provides a convenient benchmark for the evaluation of the welfare effectiveness of other well known tariff reform rules, as e.g. the proportional and the concertina rules. We develop the properties of this tariff reform, characterize the sources of the potential welfare gains from tariff reform, use it to establish conditions under which some existing reforms are locally optimal, provide geometric illustrations and compare welfare effectiveness of reforms using numerical examples. Moreover, being a general concept, we apply it to the issue of market access and examine its implications. Overall, the paper's contribution lies in presenting a theoretical concept where the focus is upon the size of welfare gains accruing from tariff reforms rather than simply with the direction of welfare effects that has been the concern of the literature.
\end{abstract}

JEL code: F15.

Keywords: Steepest ascent tariff reforms; piecemeal tariff policy; welfare; market access; small open economy.

Authors Affiliations: Raimondos-Møller: Copenhagen Business School, EPRU, CEPR and CESifö. Alan Woodland: University of Sydney.

Acknowledgments: Early discussions with Daniel Primont are gratefully acknowledged, as are the valuable comments on an earlier draft of the paper by Jim Anderson, Erwin Diewert, Arja Turunen-Red, participants at the CESifö conference on Global Economy in Munich, and seminar participants at Aarhus, Copenhagen, and Nottingham. The research was supported by the Australian Research Council and by EPRU, whose activities are financed by the Danish National Research Foundation. Carol Farbotko and Ponnuthurai Ainkaran provided valuable editorial assistance.

Corresponding Author: Professor Alan Woodland, School of Economics \& Political Science, University of Sydney, NSW 2006, Australia (A.Woodland@econ.usyd.edu.au). 


\section{Introduction}

The welfare implication of tariff reform in a small open economy has been the subject of many papers in the literature in international trade. There is now a well-established set of results that provide conditions under which welfare will rise in response to particular tariff reforms. The most general result is that a proportional reduction in tariff rates will raise welfare in a single-household economy provided only that a weak normality condition holds on preferences. Another result, known as the concertina theorem, is that the reduction of the tariff rate on the imports of a single commodity will raise welfare if that good has the highest ad valorem tariff rate and it is a net substitute for every other good. Such results fall into the class of problems of the second best. ${ }^{1}$

While this is an extensive body of literature, it is a general feature of the literature that each potential reform is treated separately and the main concern is with whether welfare rises or falls. Within this context, the main purposes of the present paper are to propose a new tariff reform concept and to use this new concept to provide a framework within which all particular tariff reforms can be compared in terms of their effectiveness in generating welfare gains. In this sense, while the literature on tariff reforms has been focused on the sign of the welfare effect of a tariff reform, we focus on the relative sizes of these welfare effects induced by different reform rules.

Accordingly, to this end, we propose a tariff reform that is locally optimal amongst all feasible tariff reforms. We refer to this reform as the steepest ascent tariff reform, since the idea for it arises from the steepest ascent algorithm designed to numerically maximize a function of several variables. Starting at an equilibrium established under an initial tariff setting, we formulate the differential tariff reform problem as one of choosing an arbitrarily small tariff change vector that will raise welfare. There will generally be a set of such tariff reform directions that are welfare improving. We formulate the locally optimal tariff reform problem as one of choosing a direction of reform that maximizes the gain in welfare, subject to the feasible set of tariff reforms belonging to a sphere of arbitrarily

\footnotetext{
${ }^{1}$ The early literature on tariff reform in open economies includes Meade (1955), followed by Lloyd (1974), Hatta (1977a, 1977b) and Fukushima (1979). More recent contributions to this literature include Abe (1992), Diewert, Turunen-Red and Woodland (1989, 1991), Turunen-Red and Woodland (1991), Anderson and Neary $(1992,1996)$ and Neary (1995).
} 
small radius. We show that the locally optimal, or steepest ascent, tariff reform is one that has a direction of change proportional to the gradient of the indirect utility function with respect to the tariff vector. While the concept of a steepest ascent tariff reform has not previously appeared in the international trade literature (to our knowledge), it is closely related to, and inspired by, the concept of an optimal tax perturbation introduced into the tax reform literature by Diewert (1978, p.152). In a similar vein to our reform concept, Tirole and Guesnerie (1981) make use of a related gradient projection tax reform in a closed economy with many consumers and a social welfare function, but they do not compare reforms as is done here. The idea of locally optimal tax changes is also behind Weymark's (1981) concept of undominated directions of tax reform but he does not make use of a steepest ascent tax reform.

Our steepest ascent tariff reform concept is used in the paper to develop new results in the theory of tariff reform in a small open economy. First, we characterize the steepest ascent tariff reform and develop some of its properties. Being proportional to the gradient of the indirect utility function, it may be evaluated knowing the initial tariff vector and the net substitution matrix at the initial equilibrium. We are able to show that the steepest ascent tariff reform applied to the tariffs of all traded goods requires at least one tariff rate to rise and at least one tariff rate to fall as part of the reform. The proportional and concertina tariff reforms each violate this requirement in general. We also show, however, that if there is a concertina good then the steepest ascent reform requires that the tariff on this good be reduced as part of the reform.

Second, by comparing the results of applying the steepest ascent tariff reform concept to the cases where all tariff rates are subject to the reform and where only the tariffs on non-numeraire goods are permitted to be reformed, we establish that the latter involves a welfare loss compared to the former reform. That is, if we restrict the tariff reform vectors to be of equal length, it matters a great deal as to whether the tariff reform is applied to the tariff of all goods or only to those of non-numeraire goods. This may appear at first glance to contradict the well-known result that homogeneity considerations allow the equivalent analyses of tariffs on either all or non-numeraire goods, but this is not the case as will be demonstrated below. Since the literature on tariff reforms has been focused on 
the sign of the welfare effect of a tariff reform and not upon its size, the issue we raise here about the welfare loss associated with restricting reforms to non-numeraire goods has not previously been considered. Given our focus on the relative sizes of welfare gains from different tariff reforms, this issue is of significant policy importance.

Third, we use the steepest ascent tariff reform concept to provide a characterization of the sources of the potential welfare gains from tariff reform in terms of measures of the level and dispersion of initial tariff rates. These are measured by two characterizations of the level and dispersion of initial tariff distortions - the generalized average tariff and the generalized variance of tariffs - defined using the substitution matrix. The greater is the generalized average tariff rate, or the greater is the generalized variance of tariffs, the greater is the potential increase in welfare from tariff reforms. These generalized mean and variance measures of the distortions provided by the initial tariffs differ from, but are inspired by, measures of the same name recently proposed by Anderson and Neary (2006) for the evaluation of arbitrary tariff reforms. We apply their measures to our steepest ascent tariff reform and argue that the two sets of measures have different, but complementary, objectives and interpretations.

Fourth, we undertake a comparison of the proportional, univariate and steepest ascent tariff reforms. Since the latter is the locally optimal tariff reform, it provides a convenient benchmark by which all tariff reforms may be measured. We establish several results concerning this comparison. In particular, we characterize the conditions under which the proportional tariff reform and the univariate tariff reform are locally optimal. We also provide a geometric illustration of these reforms and show that the more acute the angle between a reform and the steepest ascent tariff reform, the greater will be its welfare efficiency. In doing this, we develop a new index that measures the welfare effectiveness of any tariff reform. Two numerical examples are used to provide concrete measures of the relative efficiency of the proportional and univariate reforms in raising welfare.

Fifth, we demonstrate that our steepest ascent reform concept may be applied to any policy objective by examining, e.g., the issue of market access, recently investigated by Ju and Krishna (2000) and Anderson and Neary (2006). We show the implications of the steepest ascent tariff reform for market access, and then construct a tariff reform that is 
the best (i.e. locally optimal) for raising market access and show its welfare implications. We show a surprising "duality" in these effects.

Since the steepest ascent tariff reform is locally optimal in the sense that it yields the highest level of utility of any feasible tariff reform of equal length, it provides an important benchmark for the evaluation of the welfare efficiency of any proposed tariff reform for an economy. As such, it represents a valuable theoretical concept where the focus is upon the size of welfare gains accruing from welfare reforms rather than simply with the direction of welfare effects that has been the concern of the literature. In addition to having this theoretical role, the steepest ascent tariff reform can be made operational provided information is available on the net substitution matrix for the economy at the initial equilibrium as well as the initial tariffs. Increasingly, detailed empirical estimations and computable general equilibrium models are coming available for many countries thus making the concept of practical as well as theoretical interest.

\section{Small Open Economy and Steepest Ascent Tariff Reforms}

We consider a perfectly competitive general equilibrium model of a small open economy that trades in $n$ internationally tradeable commodities. The model may be expressed as

$$
p^{\prime} S_{\pi}(\pi, u)=b
$$

in terms of the world price vector $p$ ( $p^{\prime}$ denotes the transpose of a vector), the domestic price vector $\pi=p+t$, the specific tariff vector $t$, the representative agent's utility level $u$ and the transfers abroad $b .^{2}$ In this specification, $S(\pi, u) \equiv E(\pi, u)-G(\pi)$ is the net expenditure function, being the difference between the consumer expenditure function $E$ and the gross domestic product function $G$. Also, $S_{\pi}(\pi, u) \equiv \nabla_{\pi} S(\pi, u)$ denotes the gradient of the net expenditure function with respect to prices and represents the vector

\footnotetext{
${ }^{2}$ The analysis may also be undertaken using ad valorem tariff rates or tariff factors. This task is undertaken in the Appendix.
} 
of compensated net import functions. Equation (1) is the country's budget constraint, which requires that the value at world prices, $p$, of the net import vector, $S_{\pi}$, be equal to the net transfers from abroad, $b$. If $b=0$, then the budget constraint simply requires that there is a zero balance of trade.

Let $S_{\pi \pi} \equiv \nabla_{\pi}^{2} S(\pi, u)=\nabla_{\pi} S_{\pi}(\pi, u)$ be the substitution matrix, measuring the response of compensated net imports to changes in prices, and let $S_{\pi u} \equiv \nabla_{\pi u} S(\pi, u)=\nabla_{u} S_{\pi}(\pi, u)$ be a vector of "income" effects, measuring the response of compensated net imports to changes in utility. It is assumed that the Hatta normality condition, $p^{\prime} S_{\pi u}>0$, holds. It is well known that the substitution matrix, $S_{\pi \pi}$, is a symmetric, negative semidefinite matrix satisfying the homogeneity identity that $\pi^{\prime} S_{\pi \pi}(\pi, u) \equiv 0$ for all domestic price vectors, $\pi$.

The budget constraint (1) may be solved for utility, $u$, as a function of the world price vector, $p$, and the tariff vector, $t$. This yields the indirect utility function $U(t ; p)$, which may be written more simply as $U(t)$ since the world price vector is assumed to remain fixed and so may be subsumed.

\subsection{Steepest Ascent Tariff Reforms}

We consider piecemeal reforms of tariffs. However, rather than simply consider all such reforms or some special cases, we wish to characterize piecemeal reforms that are locally optimal. That is, we want to find the direction vector, $\delta$, that maximizes the differential change in utility. Such a direction of reform is then said to be locally optimal.

Suppose that the initial tariff vector is $t^{0}$. The gradient of the indirect utility function at this initial point is $\nabla U\left(t^{0}\right)$ and the directional derivative (in direction $\delta$ ) at this initial point is expressed as $D\left(t^{0}, \delta\right)=\nabla U\left(t^{0}\right)^{\prime} \delta .^{3,4}$ This directional derivative indicates the

\footnotetext{
${ }^{3}$ Let $f$ be a numerical function defined on an open set $X$ in $R^{n}$ and let $x \in X$. Let $\delta \in R^{n}$. The directional derivative of $f$ at $x^{0}$ in direction $v$ is

$$
D_{\delta} f\left(x^{0}\right) \equiv \lim _{h \rightarrow 0} \frac{f\left(x^{0}+h \delta\right)-f\left(x^{0}\right)}{h},
$$

when the limit exists. See, for example, Apostol (1957, 104-105).

${ }^{4}$ The directional derivative is related to the recent work by Fare and Primont (2006) on directional duality theory.
} 
slope of the indirect utility function in the direction $\delta$. We wish to find a direction that maximizes the slope of the indirect utility function, since this is the direction of a differential (piecemeal) tariff reform that yields the greatest improvement in utility; reforms of tariffs in all other directions will yield lower increases in utility. ${ }^{5}$ For this task to be well defined, it is necessary to impose a restriction on the direction vectors to ensure that they are of equal length. Accordingly, feasible direction vectors are restricted to lie in a sphere of radius $l, C(l) \equiv\left\{\delta:\left(\delta^{\prime} \delta\right)^{1 / 2} \leq l\right\}$, where $l$ is chosen to be arbitrarily small, and where $\|\delta\| \equiv\left(\delta^{\prime} \delta\right)^{1 / 2}$ defines the Euclidean length of the vector $\delta$.

Thus, the locally optimal tariff reform problem may be expressed formally as

$$
\max _{\delta}\left\{\nabla U\left(t^{0}\right)^{\prime} \delta: \delta \in C(l)\right\}
$$

It will be readily recognized that such reforms of tariff rates correspond exactly to changes implied by the steepest ascent algorithm for the maximization of the indirect utility function. Accordingly, we define the solution for $\delta$ to the problem defined by (2) as the steepest ascent tariff reform (SATR) direction. The solution for $\delta$ is given by

$$
\delta^{S}=\theta \nabla U\left(t^{0}\right), \quad \theta>0
$$

where $\nabla U\left(t^{0}\right)$ is the gradient vector, whose elements are the partial derivatives $\partial U\left(t^{0}\right) / \partial t_{i}, i=$ $1,2, \ldots, n$, and where $\theta=l /\left\|\nabla U\left(t^{0}\right)\right\|$ is a positive scalar. ${ }^{6}$ While equation (3) provides the solution for the tariff reform direction vector of length $l, \delta^{S}$, the steepest ascent tariff reform may be expressed more generally as a change in the tariff vector of the form $d t=\delta^{S} d \alpha, d \alpha>0$, where the scalar $d \alpha$ indicates the size of the tariff reform.

In the present context, it can be shown that the gradient of the indirect utility function

\footnotetext{
${ }^{5}$ Of course, some directions may yield lower utility.

${ }^{6}$ The steepest ascent algorithm provides the motivation for our locally optimal tariff reform. The steepest ascent algorithm uses this direction and a step size to move to a new tax point from an initial or starting point, this move constituting the first iteration. Having reached a new point, the same steepest ascent method is used to move to the next tax point. The algorithm converges once the gradient becomes sufficiently close to the zero vector. In our context, one can imagine a sequence of small discrete tariff reforms, each of which is restricted to a sphere of radius $l$, chosen to be some small scalar. If this algorthm converges, then the point of convergence will be a local optimum. For a description and properties of the steepest ascent algorithm for the unconstrained maximization of a function of several variables see, for example, Luenberger (1984, 214-220), Press et al. (1986, ch. 10) and Bhatti (2000, ch. 5).
} 


$$
\nabla U\left(t^{0}\right)=S_{\pi \pi}\left(\pi^{0}, u^{0}\right) t^{0} / p^{\prime} S_{\pi u}\left(\pi^{0}, u^{0}\right)
$$

where $\pi^{0}=p+t^{0}$ is the domestic price vector and $u^{0}$ is the utility level at the initial tariff vector $t^{0} \cdot{ }^{7}$ Accordingly, we can use this result to obtain the steepest ascent tariff reform as in the following proposition.

Proposition 1 The steepest ascent tariff reform is given by $d t=\delta^{S} d \alpha, d \alpha>0$, where

$$
\delta^{S}=\lambda S_{\pi \pi}\left(\pi^{0}, u^{0}\right) t^{0}
$$

$\lambda=\theta / H>0$ and $H \equiv p^{\prime} S_{\pi u}\left(\pi^{0}, u^{0}\right)>0$ is the Hatta normality term.

The interpretation of the steepest ascent tariff reform may be assisted by reference to Figures 1 and 2. Figure 1 shows iso-utility contours in domestic price space with just two commodities. These indifference curves are rays emanating from the origin due to the fact that the net expenditure function is homogeneous of degree one and, hence, the indirect utility function is homogeneous of degree zero, in domestic prices. Point $A$ (corresponding to free trade, with the domestic price vector equalling the world price vector, $p$ ) is the highest utility point corresponding to free trade, but all points along the ray through $A$ have the same utility. Point $B$ denotes the initial domestic price vector arising from the initial tariff vector $t^{0}$, which involves an import tariff on good 1 and free trade in good 2 . The tangent to the indifference curve passing through point $B$ is the indifference curve itself and orthogonal (at right angle) to the tangent is the gradient vector, as depicted. This gradient vector indicates the direction of steepest ascent at the point $B$, and so is the direction of the steepest ascent tariff reform. This reform requires a decrease in the tariff rate on good 1 but an increase in the tariff rate on good 2 (which is initially zero).

\footnotetext{
${ }^{7}$ To obtain this result, totally differentiate (1) to get $p^{\prime} S_{\pi u}\left(\pi^{0}, u^{0}\right) d u+p^{\prime} S_{\pi \pi}\left(\pi^{0}, u^{0}\right) d t=0$. Because the net expenditure function is homogeneous of degree zero in domestic prices, it follows that the substitution matrix $S_{\pi \pi}$ must obey the identity $\pi^{\prime} S_{\pi \pi}\left(\pi, u^{0}\right) \equiv 0$ for all domestic price vectors $\pi$. Noting that $\pi=p+t$, this identity may be expressed as $t^{\prime} S_{\pi \pi}\left(\pi, u^{0}\right) \equiv-p^{\prime} S_{\pi \pi}\left(\pi, u^{0}\right)$. The above total derivative may then be written as $p^{\prime} S_{\pi u}\left(\pi^{0}, u^{0}\right) d u-t^{0 \prime} S_{\pi \pi}\left(\pi^{0}, u^{0}\right) d t=0$. Thus, we obtain the effect of a change in tariffs upon utility as $d u=t^{0 \prime} S_{\pi \pi}\left(\pi^{0}, u^{0}\right) d t / p^{\prime} S_{\pi u}\left(\pi^{0}, u^{0}\right)$. This provides the formula for the gradient of the indrect utility function with respect to the tariff vector as expressed in the text.
} 
It achieves the greatest increase in utility of any direction of tariff reform of the same length.

Figures 1 and 2: (about here)

Figure 2 illustrates the steepest ascent tariff reform for an economy with three traded goods. To facilitate this illustration in two dimensions, we assume that good 3 is the numeraire good, that the tariff on this good is zero and that the tariff reform is restricted to the non-numeraire goods (as is the common custom in the literature). The figure shows the iso-utility contours in the domestic price space for the non-numeraire goods. Point $A$ is the highest utility point corresponding to free trade. Point $B$ denotes the initial domestic price vector arising from the initial tariff vector $t^{0}$. The tangent to the indifference curve passing through point $B$ is depicted in the figure, as is the gradient vector, which is orthogonal to the tangent of the indifference curve at point $B$. As in the previous figure, this vector indicates the direction of steepest ascent at the point $B$. This is the direction of the steepest ascent tariff reform.

Figure 2 also illustrates a path of a continuum of steepest ascent tariff reforms. At each point on the path, the direction of change is the direction of steepest ascent. Clearly, this path ends at the global maximum of the indirect utility function, since it has been implicitly assumed that there is a unique local maximum. ${ }^{8}$

\subsection{Properties of Steepest Ascent Tariff Reforms}

The steepest ascent tariff reforms have several interesting and useful features that we now record and discuss.

First, it is shown that, not surprisingly, steepest ascent tariff reforms always increase utility except at a (local) optimum. To see this, we calculate the value of the directional derivative $D\left(t^{0}, \delta\right)=\nabla U\left(t^{0}\right)^{\prime} \delta$ at the optimally chosen direction. ${ }^{9}$ In the tariff reform

\footnotetext{
${ }^{8}$ This figure thus illustrates the (continuous version of the) steepest ascent algorithm for the maximization of the indirect utility function.

${ }^{9}$ In general this is given by $d U^{S} / d \alpha=D\left(t^{0}, \delta^{S}\right)=\nabla U\left(t^{0}\right)^{\prime} \delta^{S}=\theta \nabla U\left(t^{0}\right)^{\prime} \nabla U\left(t^{0}\right)>0$, where the inequality follows because the inner product of any vector with itself is positive (unless the vector is the null vector), being the sum of squares of its elements. This inequality establishes that the steepest ascent tariff reform always raises welfare, irrespective of the initial tariff vector or the nature of the economy,
} 
context, the change in utility is given by

$$
\begin{aligned}
d U^{S} / d \alpha & =D\left(t^{0}, \delta^{S}\right) \\
& =\left(\lambda / H^{2}\right) t^{0 \prime} S_{\pi \pi}^{\prime}\left(\pi^{0}, u^{0}\right) S_{\pi \pi}\left(\pi^{0}, u^{0}\right) t^{0} \\
& =\theta^{-1} \delta^{S \prime} \delta^{S}>0 .
\end{aligned}
$$

Being the inner product of the direction vector $\delta^{S}$ with itself, the directional derivative is positive provided $\delta^{S}=\lambda S_{\pi \pi}\left(\pi^{0}, u^{0}\right) t^{0} \neq 0$. Turunen-Red and Woodland (2001) define the vector $S_{\pi \pi}\left(\pi^{0}, u^{0}\right) t^{0}$ as a "local measure of tariff distortion", each element measuring the distortion for each good. Accordingly, we see that the steepest ascent tariff reform yields an increase in utility provided there is at least one good that has a tariff distortion, as defined by Turunen-Red and Woodland. Clearly, the increase in utility will be zero if, and only if, $\delta^{S}=\lambda S_{\pi \pi}\left(\pi^{0}, u^{0}\right) t^{0}=0$, which means that there are no tariff distortions. ${ }^{10}$

A second property is not obvious and has important implications for locally optimal tariff reforms.

Proposition 2 Steepest ascent (locally optimal) tariff reforms on all goods require an increase in the tariff rate of at least one product and a decrease in the tariff rate of at least one product.

Proof. Pre-multiply the steepest ascent tariff reform by the domestic price vector to get

$$
\pi^{0 \prime} \delta^{S}=\lambda \pi^{0 \prime} S_{\pi \pi}\left(\pi^{0}, u^{0}\right) t^{0}=0
$$

since $\pi^{0 \prime} S_{\pi \pi}\left(\pi^{0}, u^{0}\right)=0$ from the homogeneity properties of the net expenditure function. Since $\pi^{0}$ is positive, by assumption, it is clear that $\delta^{S}$ has to have both positive and negative elements.

provided that the gradient of the utility function does not vanish.

${ }^{10}$ In general, this does not necessarily mean that $t^{0}=0$. For example, there will be no distortions if there are non-zero tariffs but the substitution matrix vanishes $\left(S_{\pi \pi}=0\right)$. This is the case if equilibrium occurs where the production possibilities frontier and the indifference curve have a "corner". In general, no tariff distortions imply that $t^{0}=\kappa \pi^{0}$ if $S_{\pi \pi}$ has maximal rank $n-1$, since $\pi^{0 \prime} S_{\pi \pi}\left(\pi^{0}, u^{0}\right)=0$ from the homogeneity properties of the net expenditure function. In this case, $t^{0}$ is proportional to the world price vector $p$, a special case of which is $t^{0}=0$. 
This proposition is interesting, since the conventional wisdom is that one gets welfare improvements by reducing tariff distortions. However, according to this proposition, locally optimal reforms require that the tariff rate on at least one product be increased along with a reduction in the tariff on at least one other product. ${ }^{11}$ Of course, as usual, we have to be careful here in the interpretation of the proposition as the 'tariff' is really a trade tax - a tariff on an imported good, but a subsidy on an exported good. The importance of this proposition will be developed further below.

It is evident from the expression for the steepest ascent tariff reform that the sign structure of $\delta^{S}$ depends upon the initial tariff vector, $t^{0}$, and the initial substitution matrix, $S_{\pi \pi}\left(\pi^{0}, u^{0}\right)$, and upon how these combine. To get some understanding of this relationship, we write out the elements of $\delta^{S}$ in component form and express them in a form that lends itself to interpretation. Specifically, we examine the steepest ascent direction of reform to determine situations when a tariff on a good will be reduced and situations when the tariff will be raised.

The locally optimal direction for tariff reform may be expressed as follows. In this expression, the reform for product $i$ is written as:

$$
\begin{aligned}
\delta_{i}^{S} & =\lambda \sum_{j=1}^{n} S_{i j}\left(\pi^{0}, u^{0}\right) t_{j}^{0}, \quad \lambda>0, \\
& =-\lambda \sum_{j \neq i}^{n} S_{i j}\left(\pi^{0}, u^{0}\right)\left(\sigma_{i}^{0}-\sigma_{j}^{0}\right) \pi_{j}^{0}, \quad i=1,2, \ldots, n .
\end{aligned}
$$

This expression gives an indication of how the locally optimal direction of tariff change relates to the (cross-product) substitution terms $S_{i j}$ and the ad valorem (with domestic price bases) tariff rates $\sigma_{j}^{0} \equiv t_{j}^{0} / \pi_{j}^{0}$.

In general, expression (7) indicates the requirements for a locally optimal reform to involve an increase $\left(\delta_{i}^{S}>0\right)$ or a decrease $\left(\delta_{i}^{S}<0\right)$ in the tariff rate on a good $i$. The higher is the tariff on good $i$ relative to other tariff rates and the more substitutable good $i$ is with other goods, the more likely it is that a locally optimal tariff reform involves a

\footnotetext{
${ }^{11}$ The proposition does not apply to the case where the tariff reform is restricted to non-numeraire goods, which is dealt with in the next subsection.
} 
reduction in the tariff on good $i$. Conversely, if good $i$ is complementary with a good $j$ $\left(S_{i j}<0\right)$ and it has a lower tariff than $j$ then that combination contributes to a reduction in the tariff rate on good $i$. That is about as much that (7) allows us to say in general.

However, more precise statement may be made if we are prepared to make assumptions about the initial tariffs and the sign structure of the initial substitution matrix. To illustrate this point and to thereby get a better understanding of this expression, consider a concertina commodity. We say that good $i$ is a concertina commodity if (a) $\sigma_{i}^{0}-\sigma_{j}^{0}>0$ for all $j \neq i$ and (b) $S_{i j}\left(\pi^{0}, u^{0}\right)>0$ for all $j \neq i$. Thus, good $i$ is a concertina commodity if it has the highest ad valorem tariff rate and it is a net substitute for all other goods. Under this definition, we see that the right hand side of (7) is negative. Thus, the locally optimal tariff reform involves a reduction in the tariff rate on a concertina good. ${ }^{12}$ Accordingly, we get a very precise result from (7) if good $i$ has concertina good properties: if a concertina good exists, the steepest ascent reform demands that its tariff be reduced as part of the reform. ${ }^{13}$

Proposition 3 If a concertina good exists, the steepest ascent reform demands that its tariff be reduced as part of the reform.

Of course, there can be at most a single concertina good so there always remains the issue of whether the tariffs on the non-concertina goods rise or fall as part of the steepest ascent reform. As a final observation, it is important to distinguish the above proposition from the well-known concertina theorem. This theorem states that a unilateral reduction of the tariff on a concertina commodity (as defined above) is guaranteed to raise welfare. By contrast, our steepest ascent tariff reform involves the reform of all tariffs. What the above proposition establishes is that, as part of that reform, the tariff on a concertina good is to be reduced.

\footnotetext{
${ }^{12}$ Those familiar with the proof that a reduction on the tariff of a concertina good (alone) is welfare improving will observe that this is almost the same as that proof. To prove the concertina theorem, we calculate the directional derivative $D\left(t^{0},-e_{i}\right)=-\nabla U\left(t^{0}\right)^{\prime} e_{i}=-H^{-1} \sum_{j=1}^{n} S_{i j}\left(\pi^{0}, u^{0}\right) t_{j}^{0}$. This is precisely what we have done, since our locally optimal direction is proportional to the gradient of the indirect utility function.

${ }^{13}$ On the other hand, if good $i$ satisfies property (b) but has the lowest ad valorem tariff rate (the opposite of property (a)), then the right hand side of (7) is positive and so the tariff rate on such a good is to be raised. Again, we get a precise result.
} 


\subsection{Restricted or Normalized Reforms}

Because the indirect utility function is homogeneous of degree zero in domestic prices, only relative domestic prices matter. Accordingly, without any loss in generality, the (positive) domestic price of one good (say the first) can be normalized by setting it equal to the world price of the first good (for example), thus implying that the tariff on this good has been set to zero. Because of this, it is customary to choose the first good as the numeraire (with unit price) and to assume that its tariff is zero and remains such in the tariff reform process.

To invoke these assumptions, we choose good 1 as the numeraire whose tariff is set at zero and define $\pi^{\prime}=\left(\begin{array}{ll}1 & \rho^{\prime}\end{array}\right), p^{\prime}=\left(\begin{array}{ll}1 & q^{\prime}\end{array}\right)$ and $t^{\prime}=\left(\begin{array}{ll}0 & \tau^{\prime}\end{array}\right)$. Thus, $q$ denotes the world price vector for non-numeraire goods, $\rho$ denotes the domestic price vector for non-numeraire goods and $\tau$ denotes the vector of tariffs on non-numeraire goods. The substitution matrix may be similarly decomposed.

Invoking these assumptions, it is evident that the steepest ascent reform requires us to only use the gradient without the first element. Thus, the steepest ascent direction for non-numeraire goods may be expressed as

$$
\delta_{\rho}^{S}=\lambda_{\rho} S_{\rho \rho}\left(\pi^{0}, u^{0}\right) \tau^{0}, \quad \lambda_{\rho}>0
$$

where $\lambda_{\rho}=\theta_{\rho} H^{-1}$ and $\theta_{\rho}$ is the scalar needed to ensure that $\delta_{\rho}^{S}$ is of length $l$. The change in utility arising from the tariff reform $d \tau=\delta_{\rho}^{S} d \alpha, d \alpha>0$, is given by

$$
d U_{\rho}^{S} / d \alpha=\left(\theta_{\rho} H^{-2}\right) \tau^{0 \prime} S_{\rho \rho}^{\prime}\left(\pi^{0}, u^{0}\right) S_{\rho \rho}\left(\pi^{0}, u^{0}\right) \tau^{0}>0
$$

These two expressions, for the direction of tariff reform and the resulting change in utility, depend only upon the portion of the substitution matrix relating to non-numeraire goods, $S_{\rho \rho}$.

It is customary in the literature to assume that the numeraire good is not subject to tariffs and that the tariff reform is therefore restricted to non-numeraire goods. This can always be done without loss of generality, as is well known. The reasons for this custom 
being valid are that the equilibrium is homogeneous of degree zero in domestic prices (only price ratios matter) and that the equilibrium domestic price ratios can be obtained by an infinity of tariff vectors. Accordingly, to obtain a unique tariff vector it is required that the tariff vector be normalized in some way. Specifically, the tariff vector can always be chosen with the tariff rate on any one good being zero and it is customary to choose this good to be the numeraire. The consequence is that we can undertake our analysis of tariffs in a model where there is a numeraire that is not taxed and not subject to the tariff reform or, equivalently, undertake the analysis using all goods. The equilibrium for all quantities will be unaffected by this choice.

This point may be illustrated in Figure 3. In this figure, good 2 is the numeraire and point $B$ is the domestic price vector that corresponds to a tariff on good 1 and free trade in good 2. A reform that moves the domestic price vector to point $C$ involves changes in both tariffs. Because the indirect utility function is homogeneous of degree zero in domestic prices, an equivalent equilibrium occurs at point $D$. At point $D$ the domestic price ratio is the same as at point $C$, while the tariff vector has been changed so that there is a (now lower) tariff on good 1 but no tariff on good 2. Thus, the argument goes, we can always do this and so we may as well restrict our tariff analysis to the reform of tariffs on non-numeraire goods.

Figure 3: (about here)

In the present context of piecemeal tariff reform in which the tariff reform vector is restricted, say to a sphere of radius $l$, this equivalence breaks down. The reason for the difference in result is that, in the present context, we do not have the freedom in choice of tariffs to ensure this equivalence. To demonstrate the validity of this statement, we utilize Figure 3. In that figure, the move from initial point $B$ to point $C$ constitutes a reform of all tariffs. The equivalence argument (expressed above) is that this new domestic price point $C$ can be contracted to point $D$, which is welfare equivalent, by a suitable choice of change of tariffs to a tariff vector that has a zero tariff on good 2 (here the numeraire). That option is not open to the tariff authority if the tariff reform vector is to lie on 
the sphere of radius $l$ (shown with centre $B$ and radius the length of vector $B C$ ). A contraction of domestic price vector $C$ to one that involves no tariff on the numeraire good necessarily takes us to point $D$. However, point $D$ lies outside the sphere of radius $l$ that is centred on point $B$. A tariff reform from $B$ in the direction of $D$ of the same length as the reform from $B$ to $C$, shown as point $E$, must fall short of point $D$. Accordingly, the reform of the non-numeraire tariffs alone cannot be as welfare improving as the reform of all tariffs. Thus, reforms of the tariffs of non-numeraire goods only is not equivalent to reforms of the tariffs of all goods of the same length. There is a welfare loss to restricting attention to non-numeraire goods imposed by the constraint of restricting the reforms to be in the same sphere. Thus, we have:

Proposition 4 Suppose that tariff reforms are restricted to a sphere of radius $l$. Then a tariff reform on non-numeraire goods only involves a welfare loss compared to a tariff reform of the tariffs on all goods.

This proposition has important implications for the comparison of the welfare effectiveness of different tariff reforms. It must be carefully interpreted, however. Clearly, it is the restriction of a policy reform to a subset (here a sphere) of the tariff space that is the important premise underlying this proposition. By imposing this restriction, the opportunity to take any resulting domestic price vector and contract it along a price ray to a point where the tariff on the numeraire good is zero is removed.

The more basic question that needs to be addressed is that of why such a restriction is relevant. It is not relevant if the task at hand is to determine the welfare implications of a particular tariff reform or to construct a tariff reform. In this case, the analysis can proceed using either the full tariff vector or the restricted tariff vector. It is relevant, however, if the primary purpose is to compare the welfare effectiveness of different policy reforms. To provide a basis for comparison, the permissible reforms should be restricted to the same set. If they are not, then the welfare effectiveness of different reforms may be due to choosing reforms that are of different sizes. We wish to compare different tariff reforms and so the proposition is relevant to our task. 


\section{Sources of Potential Welfare Gains}

It was shown above that the steepest ascent tariff reform is welfare improving and is locally optimal in that it provides the highest level of welfare increase of any tariff reform of the same length. Here we show that the increase in welfare may be expressed in terms of two "sufficient statistics" that fully describe the distortions in the tariff structure. We call these the generalized mean and generalized variance, but it must be emphasized that these are different from (but inspired by) the concepts of the same name introduced by Anderson and Neary (2006).

\subsection{A Welfare Gain Decomposition}

The change in welfare is expressed by (9). We explicitly deal with a tariff reform on non-numeraire goods only, the tariff on the numeraire being set to zero. This is without loss of generality, since the purpose here is to measure the welfare effects of a tariff reform and not to compare several reforms. To simplify notation, we write $\Sigma=S_{\rho \rho}\left(\pi^{0}, u^{0}\right)$ and let $\tau$ be the initial tariff vector of non-numeraire goods (without the 0 superscript). Thus, the welfare change arising from the steepest ascent tariff reform applied to non-numeraire goods may be expressed as

$$
\eta^{-1} d U^{S} / d \alpha=\tau^{\prime} \Sigma^{\prime} \Sigma \tau
$$

where $\eta=\lambda_{\rho}^{2} / \theta_{\rho}=\theta_{\rho} / H^{2}$ is a scalar. This expression may be rewritten in terms of new concepts describing the level and dispersion of the initial tariff rates, namely the generalized mean tariff rates and the generalized variances and covariances of the tariff rates, as demonstrated in the following proposition.

Proposition 5 The change in utility for the steepest ascent tariff reform may be expressed as

$$
\eta^{-1} d U^{S} / d \alpha=\tau^{\prime} \Sigma^{\prime} \Sigma \tau=V+s \bar{\tau}^{2}
$$

where $s \equiv \iota^{\prime} \Sigma^{\prime} \Sigma \iota>0, \bar{\tau} \equiv \iota^{\prime} \Sigma^{\prime} \Sigma \tau / s$ and $V \equiv(\tau-\iota \bar{\tau})^{\prime} \Sigma^{\prime} \Sigma(\tau-\iota \bar{\tau})$.

Proof. Consider any scalar $\bar{\tau}$ and let $\iota$ be a vector of ones. Write the change in utility as $\eta^{-1} d U^{S} / d \alpha=\tau^{\prime} \Sigma^{\prime} \Sigma \tau=(\tau-\iota \bar{\tau}+\iota \bar{\tau})^{\prime} \Sigma^{\prime} \Sigma(\tau-\iota \bar{\tau}+\iota \bar{\tau})=(\tau-\iota \bar{\tau})^{\prime} \Sigma^{\prime} \Sigma(\tau-\iota \bar{\tau})+$ 
$\bar{\tau}^{2} \iota^{\prime} \Sigma^{\prime} \Sigma \iota+2(\tau-\iota \bar{\tau})^{\prime} \Sigma^{\prime} \Sigma \iota \bar{\tau}$. Defining $V \equiv(\tau-\iota \bar{\tau})^{\prime} \Sigma^{\prime} \Sigma(\tau-\iota \bar{\tau})$, the first term is $V$. Defining $s \equiv \iota^{\prime} \Sigma^{\prime} \Sigma \iota>0$, the second term becomes $s \bar{\tau}^{2}$. Finally, the third term becomes zero if we define $\bar{\tau}$ as $\bar{\tau} \equiv \iota^{\prime} \Sigma^{\prime} \Sigma \tau / s$.

In this expression, $\bar{\tau}$ is defined as the generalized mean tariff rate. It is readily shown that $\bar{\tau}=\beta$ if all tariffs equal the scalar $\beta(\tau=\beta \iota)$. If $\Sigma^{\prime} \Sigma$ were to be the identity matrix, then $\bar{\tau}$ would coincide exactly with the arithmetic mean of the tariff rates. The transformation of the tariff rates by the matrix $\Sigma^{\prime} \Sigma$ leads to the use of the qualifier "generalized" in the name of $\bar{\tau}$ as the generalized mean tariff rate. In a similar fashion, $V$ would be the conventional variance of the tariff rates if $\Sigma^{\prime} \Sigma$ had been the identity matrix; again, use of matrix $\Sigma^{\prime} \Sigma$ in the definition leads to the use of "generalized" in the name of $V$. The generalized variance will be positive unless all tariff rates are equal, in which case it becomes zero. Clearly, therefore, $\bar{\tau}$ and $V$ respectively measure the level and the dispersion of the tariff rates.

Proposition 5 is useful in that it provides a description of the sources of welfare gain from the steepest ascent tariff reform expressed in terms of the level and dispersion of the initial tariff rates. This formula has several interesting features and properties. First, both the mean and variance enter the formula positively, meaning that the welfare gain is higher the greater is the generalized mean and the greater is the generalized variance. Second, this implies that the welfare gain from a steepest ascent tariff reform is greater the higher is the overall level of tariffs as measured by the generalized mean, $\bar{\tau}$. This makes sense, since large distortions suggest that tariff reform will be effective. Third, it also implies that the welfare gain is greater the greater is the overall dispersion of the tariff rates, as measured by the generalized variance, $V$. This indicates that it is not just levels, but dispersion of tariff rates that characterize distortions. Fourth, the generalized mean and variance measure different aspects of the tariff distortion. Even if the variance is zero, there is still a distortion if the uniform tariff rate on non-numeraire goods is nonzero (and the tariff on the numeraire is zero, it is recalled). Conversely, even if the mean tariff rate were zero, there would be a distortion if the tariff rates were dispersed (they are non-zero). 


\subsection{The Anderson-Neary Welfare Gain Decomposition}

Anderson and Neary (2006) have recently introduced the idea of describing tariff reforms in terms of changes in the generalized mean and generalized variance of the tariff structure. They show that the change in welfare from an arbitrary tariff reform may be expressed in terms of these changes in the generalized mean and generalized variance. In the following, we use this idea to evaluate the steepest ascent tariff reform. Specifically, we obtain their decomposition, which applies to any arbitrary tariff reform, and then use it to examine the steepest ascent tariff reform. Our derivation is different from theirs and so provides an alternative access to their result.

Proposition 6 (Anderson and Neary, 2005). The change in welfare from an arbitrary (non-numeraire) tariff reform, $d \tau$, may be expressed as

$$
H d U=\tau^{\prime} \Sigma^{\prime} d \tau=\left(-0.5 d V^{\mathrm{AN}}-\bar{\tau}^{\mathrm{AN}} d \bar{\tau}^{A N}\right) \bar{s}
$$

where $\bar{s} \equiv-\iota^{\prime} \Sigma \iota>0, \bar{\tau}^{A N} \equiv-\iota^{\prime} \Sigma \tau / \bar{s}, d \bar{\tau}^{A N} \equiv-\iota^{\prime} \Sigma d \tau / s$ and $d V^{A N} \equiv 2\left(\tau-\iota \bar{\tau}^{A N}\right)^{\prime} \Sigma d \tau / \bar{s}$.

Proof. Consider any scalar $\bar{\tau}$ and let $\iota$ be a vector of ones. Write the change in utility as $H d U=\tau^{\prime} \Sigma^{\prime} d \tau=(\tau-\iota \bar{\tau}+\iota \bar{\tau})^{\prime} \Sigma(d \tau-\iota d \bar{\tau}+\iota d \bar{\tau})=(\tau-\iota \bar{\tau})^{\prime} \Sigma(d \tau-\iota d \bar{\tau})+\bar{\tau} \iota^{\prime} \Sigma \iota d \bar{\tau}+(\tau-$ $\iota \bar{\tau})^{\prime} \Sigma \iota d \bar{\tau}+\bar{\tau} \iota^{\prime} \Sigma(d \tau-\iota d \bar{\tau})=(\tau-\iota \bar{\tau})^{\prime} \Sigma d \tau+\bar{\tau} \iota^{\prime} \Sigma \iota d \bar{\tau}+\bar{\tau} \iota^{\prime} \Sigma(d \tau-\iota d \bar{\tau})$. Define $\bar{s} \equiv-\iota^{\prime} \Sigma \iota>0$, $\bar{\tau}^{A N} \equiv-\iota^{\prime} \Sigma \tau / s, d \bar{\tau}^{A N} \equiv-\iota^{\prime} \Sigma d \tau / s$ and $d V^{A N} \equiv 2\left(\tau-\iota \bar{\tau}^{A N}\right)^{\prime} \Sigma d \tau / \bar{s}$. Then, replacing $\bar{\tau}$ by $\bar{\tau}^{A N}$ and $d \bar{\tau}$ by $d \bar{\tau}^{A N}$ everywhere, the first term in the welfare change expression is $\frac{1}{2} \bar{s} V^{A N}$, while the second term becomes $\overline{s \tau}^{A N} d \bar{\tau}^{A N}$. Finally, the third term becomes zero. Thus, the change in utility is as expressed in the proposition.

Several remarks concerning the interpretation of this proposition and its distinction from Proposition 5 are in order. First, this proposition (virtually) yields the AndersonNeary result. ${ }^{14}$ This derivation, which differs from that of Anderson and Neary, has the advantage of showing how the welfare change is decomposed, and why their definitions arise "naturally" and how they work. Second, our construction merely defines the change

\footnotetext{
${ }^{14}$ We use the qualifier "virtually" because we have not expressed the result in terms of their ad valorem rates $T=\underline{\pi}^{-1} t$, where $\underline{\pi}$ is the matrix diagonalization of vector $\pi$. This can be done easily, but is not necessary for our purposes. Numerically, our result coincides exactly with theirs.
} 
in the generalized variance. The generalized variance itself does not enter the expressions, but may be defined, as in Anderson and Neary, as $V^{A N} \equiv\left(\tau-\iota \bar{\tau}^{A N}\right)^{\prime} \Sigma\left(\tau-\iota \bar{\tau}^{A N}\right)$. Notice, also, that the Anderson and Neary formulae involve the negative definite "generalizing matrix" $\Sigma$, whereas our definitions further above involve the positive definite matrix $\Sigma^{\prime} \Sigma$. Third, while the two propositions both provide expressions for the welfare gain from a tariff reform, Proposition 6 provides this for an arbitrary reform while Proposition 5 is concerned only with the steepest ascent tariff reform. Fourth, while both propositions use the concept of generalized means and variances, Proposition 6 is expressed mainly in terms of changes in these measures implied by the tariff reform, whereas our Proposition 5 is concerned with the generalized means and variances of the initial tariff structure. (As noted above, the generalized variance itself is redundant in Anderson and Neary's proposition.)

This remark influences how the two propositions are to be interpreted and analyzed. The larger are our generalized means and variance, the greater the tariff distortion and hence the great is the welfare gain from the steepest ascent tariff reform (which, being locally optimal, determines the greatest attainable gain). By contrast, Proposition 6 shows that the greater the reduction in Anderson and Neary generalized mean and variance, the greater the welfare gain. Accordingly, although the generalized mean and variance concepts are different, the two propositions have complementary interpretations.

Anderson and Neary use their decomposition to analyze various tariff reform formulae that have been proposed in the literature, such as the proportional tariff reduction, a proportional reduction to a uniform rate and the concertina reform. Here we examine the change in Anderson and Neary's generalized mean and variance for the steepest ascent tariff reform. This yields the following proposition.

Proposition 7 The changes in the Anderson-Neary generalized mean and variance for the steepest ascent tariff reform are

$$
\begin{aligned}
d \bar{\tau}^{A N} & =-\iota^{\prime} \Sigma^{\prime} \Sigma \tau / \bar{s} \\
d V^{A N} & =2\left(\tau-\iota \bar{\tau}^{A N}\right)^{\prime} \Sigma^{\prime} \Sigma \tau=2 \tau^{\prime}\left(\bar{s} I-\Sigma^{\prime} \iota \iota^{\prime}\right) \Sigma^{\prime} \Sigma \tau
\end{aligned}
$$


Proof. These results follow by substituting $d \tau=\Sigma \tau$ into the expressions for the changes in the generalized mean and variance and simplifying.

It does not appear to be possible to sign these expressions in general. Neither is a quadratic form; indeed, both are bilinear forms. An examination of these expressions suggests that either sign is possible, depending upon the initial conditions, for the change in the Anderson-Neary generalized mean and variance arising from the steepest ascent tariff reform (even for three products). This conclusion was confirmed by numerical simulations of example problems (to be reported on further below). Most example problems involved a reduction in both the generalized mean and variance, which implies that the steepest ascent tariff reform reduced both sources of distortion (mean and variance) and so both reductions lead to welfare gains, in accordance with Anderson and Neary's results. However, some example problems exhibited an increase in the mean and a reduction in the variance, for instance. In such cases, the Anderson and Neary decomposition in Proposition 7 is not helpful in establishing whether a welfare gain occurs. On the other hand, we know that there is always a welfare gain from the use of the steepest ascent tariff reform.

\section{Welfare Efficiency of Existing Tariff Reforms}

Having examined in detail the properties of the steepest ascent tariff reform, we now compare it with the well-known reforms examined in detail in the existing literature. We start with some theoretical results concerning the optimality of some existing tariff reforms, then compare these reforms and finally move on to some numerical simulations that exemplify the main points of our analysis.

Since the steepest ascent tariff reform is locally optimal, it forms a benchmark by which any other tariff reform formula may be evaluated. The two most familiar tariff reforms for a small open economy are (a) proportional reductions in all tariffs and (b) the concertina tariff reform, whereby the highest ad valorem rate is reduced (or the lowest ad valorem rate is increased). The concertina reform is simply a univariate reform, where the good is chosen with special characteristics. Formally the proportional and univariate 
tariff reforms are defined in terms of the reform direction vectors, which are given by

$$
\begin{aligned}
\delta^{P} & =-l t^{0} /\left\|t^{0}\right\| \\
\delta^{i} & =-l e_{i}, \quad(i=1,2, \ldots, n),
\end{aligned}
$$

where $e_{i}$ is the $i$ th unit vector. These direction vector have the property that they are of length $l$, as is our steepest ascent tariff reform vector, $\delta^{S}$. The implied tariff reform may be expressed in general terms as $d t=\delta d \alpha, d \alpha>0$, where $\delta$ is chosen to be $\delta^{P}, \delta^{i}$ or $\delta^{P}$. Throughout this sub-section, we allow reforms of the tariffs of all commodities, but note below that similar results hold when the reforms are restricted to the tariffs of non-numeraire goods.

The conditions under which these two tariff reforms yield an increase in welfare are well known. The proportional tariff reform yields a welfare gain without any special conditions on the substitution matrix; all that is needed is that a tariff distortion exists and that preferences satisfy the Hatta normality condition. The second of the above reforms is a univariate reform in that it involves the reduction of the tariff on good $i$ alone. The concertina result is that a welfare gain occurs for a unilateral reduction in the tariff on good $i$ under the assumption that good $i$ has the highest ad valorem tariff rate and that all other goods are net substitutes for good $i$, in addition to the normality of preferences.

While it is obvious that these reforms do not coincide with the characterization of locally optimal reforms and, hence, are locally sub-optimal, it is nevertheless interesting that each violates the requirements set out in Proposition 2. For example, while the proportional reform involves all tariffs and hence satisfies one of the conditions demanded by local optimality, it violates the requirement of the proposition that at least one tariff rate increases. ${ }^{15}$ In a similar vein, the concertina reform violates the proposition in that it only involves one tariff reduction rather than a change in all tariff rates.

It is evident from the definition of a steepest ascent tariff reform, that other piecemeal tariff reforms must be locally sub-optimal. Nevertheless, it is interesting to compare these

\footnotetext{
${ }^{15}$ This presumes all tariffs are positive. If some are negative, this formula increases the rate towards zero.
} 
reforms. To fairly compare piecemeal reforms, it is necessary to limit the lengths of the reforms to be identical, as has been done in the definitions above. Then the comparison reduces to comparing directions of reform on a sphere.

The welfare changes arising from the steepest ascent, proportional and univariate reforms defined by the direction vectors of length $l$ in equations (5), (15) and (16) may be expressed as

$$
\begin{aligned}
H d u^{S} / d \alpha & =D\left(t^{0}, \delta^{S}\right)=\left(l /\left\|S_{\pi \pi}\left(\pi^{0}, u^{0}\right) t^{0}\right\|\right) t^{0 \prime} S_{\pi \pi}^{\prime}\left(\pi^{0}, u^{0}\right) S_{\pi \pi}\left(\pi^{0}, u^{0}\right) t^{0} \\
& =l\left\|S_{\pi \pi}\left(\pi^{0}, u^{0}\right) t^{0}\right\| \\
H d u^{P} / d \alpha & =D\left(t^{0}, \delta^{P}\right)=-\left(l /\left\|t^{0}\right\|\right) t^{0 \prime} S_{\pi \pi}^{\prime}\left(\pi^{0}, u^{0}\right) t^{0} \\
H d u^{i} / d \alpha & =D\left(t^{0}, \delta^{i}\right)=-l t^{0 \prime} S_{\pi \pi}^{\prime}\left(\pi^{0}, u^{0}\right) e_{i},
\end{aligned}
$$

where $H$ is the previously defined Hatta normality term. ${ }^{16,17}$

The formulae for welfare changes arising from the steepest ascent, proportional and univariate tariff reforms may be used to provide a comparison of welfare gains from the various reforms. Before undertaking this comparison, however, we establish conditions under which the proportional and univariate tariff reforms are locally optimal.

Although it is clear from the definition of the steepest ascent tariff reform that any other tariff reform (of equal length) cannot do better than the steepest ascent tariff reform in terms of raising welfare, the interesting question arises as to whether a particular tariff reform can do as well as the steepest ascent tariff reform and, hence, be locally optimal. If it can achieve this outcome, it is also interesting to establish the conditions required for local optimality. This is a question that does not appear to have been previously addressed in the literature.

\footnotetext{
${ }^{16}$ The second expression for the welfare gain arising from the steepest ascent reform is obtained by noting the definition of the length for a vector and applying it to the distortion vector $S_{\pi \pi}\left(\pi^{0}, u^{0}\right) t^{0}$ to get the relationship $\left\|S_{\pi \pi}\left(\pi^{0}, u^{0}\right) t^{0}\right\|=\left[t^{0 \prime} S_{\pi \pi}^{\prime}\left(\pi^{0}, u^{0}\right) S_{\pi \pi}\left(\pi^{0}, u^{0}\right) t^{0}\right]^{1 / 2}$.

${ }^{17} \mathrm{It}$ is worth noting that the same welfare expression, aparrt from a constant, is obtained if the proportional tariff reform is generalized to a linear tariff reform of the form $d t=\left(\gamma t^{0}+\beta p\right) d \alpha$, where $\gamma-\beta<0$. In this case, $H d u / d \alpha=D\left(t^{0}, \gamma t^{0}+\beta p\right)=t^{0 \prime} S_{\pi \pi}^{\prime}\left(\pi^{0}, u^{0}\right)\left(\gamma t^{0}+\beta p\right)=(\gamma-\beta) t^{0 \prime} S_{\pi \pi}^{\prime}\left(\pi^{0}, u^{0}\right) t^{0}$, since homogenetity implies that $S_{\pi \pi}\left(\pi^{0}, u^{0}\right)\left(p+t^{0}\right)=0$. When $\beta=0$ and $\gamma=-1$ the proportional tariff reduction is obtained. In general, a linear reform yields an increase in utility provided that $\gamma-\beta<0$.
} 


\subsection{Proportional Tariff Reduction Reform}

First, we consider the proportional tariff reform. We ask whether and, if so, under what circumstances will the proportional tariff reduction reform be locally optimal. The answer is provided in the following proposition.

Proposition 8 The proportional tariff reduction reform is locally optimal if, and only if, the initial tariff vector, $t^{0}$, is an eigenvector of the substitution matrix $S_{\pi \pi}\left(\pi^{0}, u^{0}\right)$.

Proof. This result is proved using the Cauchy-Schwarz inequality (Apostol, 1957, p.6), which states that $\|x\| \cdot\|y\| \geq\left|x^{\prime} y\right|$ for any two $n$-dimensional vectors $x$ and $y$. In the following, we let $x^{\prime}=t^{0 \prime} S_{\pi \pi}\left(\pi^{0}, u^{0}\right)$ and $y=t^{0}$ and apply the inequality to get that $\left|t^{0 \prime} S_{\pi \pi}^{\prime}\left(\pi^{0}, u^{0}\right) t^{0}\right| \leq\left\|t^{0 \prime} S_{\pi \pi}^{\prime}\left(\pi^{0}, u^{0}\right)\right\| \cdot\left\|t^{0}\right\|$. Using this inequality and equation (18), we obtain that $H d u^{P} / d \alpha=D\left(t^{0}, \widetilde{\delta}^{P}\right)=-\left(l /\left\|t^{0}\right\|\right) t^{0 \prime} S_{\pi \pi}^{\prime}\left(\pi^{0}, u^{0}\right) t^{0}=\left(l /\left\|t^{0}\right\|\right)\left|t^{0 \prime} S_{\pi \pi}^{\prime}\left(\pi^{0}, u^{0}\right) t^{0}\right| \leq$ $\left(l /\left\|t^{0}\right\|\right)\left\|t^{0 \prime} S_{\pi \pi}^{\prime}\left(\pi^{0}, u^{0}\right)\right\| \cdot\left\|t^{0}\right\|=H d u^{P} / d \alpha$. The equality in the Cauchy-Schwarz inequality occurs if, and only if, the vectors are proportional to one another. This means that $S_{\pi \pi}\left(\pi^{0}, u^{0}\right) t^{0}=\kappa t^{0}$ for some scalar $\kappa$. This, in turn, means that $\kappa$ is an eigenvalue for matrix $S_{\pi \pi}\left(\pi^{0}, u^{0}\right)$ and that $t^{0}$ is the corresponding eigenvector. The substitution matrix is a symmetric, negative semi-definite matrix and so has $n$ real eigenvalues and corresponding eigenvectors. Thus, there exist $n$ real valued eigenvectors of the substitution matrix $S_{\pi \pi}\left(\pi^{0}, u^{0}\right)$. If the initial tariff vector coincides with any one of these vectors, then $\left|t^{0 \prime} S_{\pi \pi}^{\prime}\left(\pi^{0}, u^{0}\right) t^{0}\right|=\left\|t^{0 \prime} S_{\pi \pi}^{\prime}\left(\pi^{0}, u^{0}\right)\right\| \cdot\left\|t^{0}\right\|$ (by the the Cauchy-Schwarz inequality) and so $d u^{P} / d \alpha=d u^{S} / d \alpha$. If the initial tariff is not equal to one of these eigenvectors, then the strict inequality $\left|t^{0 \prime} S_{\pi \pi}^{\prime}\left(\pi^{0}, u^{0}\right) t^{0}\right|<\left\|t^{0 \prime} S_{\pi \pi}^{\prime}\left(\pi^{0}, u^{0}\right)\right\| \cdot\left\|t^{0}\right\|$ holds in the Cauchy-Schwarz inequality and so $d u^{P} / d \alpha<d u^{S} / d \alpha$.

This proposition characterizes the necessary and sufficient conditions under which the proportional reduction reform is locally optimal. Of course, the condition holds trivially when $t^{0}=0$ (free trade) and when $t^{0}$ is proportional to $\pi^{0}$ (effectively free trade), but it may also hold at a non-trivial tariff vector that is an eigenvector for the substitution matrix. If the initial tariff vector is an eigenvector, local optimality of the proportional reduction reform is assured. 
While these two propositions about the optimality of the proportional tariff reduction reform relate to reforms of the tariffs on all goods, they may be readily extended to reforms on the tariffs of non-numeraire goods only. In the above statements and proofs, we simply restrict attention to non-numeraire goods and so replace $\delta^{S}$ by $\delta_{\rho}^{S}, t^{0}$ by $\tau^{0}$ and $S_{\pi \pi}$ by $S_{\rho \rho}$. To illustrate this, consider the case of just two goods with good 1 as the untaxed numeraire. Then the subscript $\rho$ simply refers to good 2 and the various non-numeraire vectors and matrices become scalars. It is then easily shown that the Cauchy-Schwarz relationship holds with equality and so the proportional reduction of the tariff on good 2 (the only tariff) is optimal. In the general, many good case, it remains the case that optimality of the proportional tariff reduction policy for all non-numeraire goods is optimal if, and only if, the non-numeraire tariff vector is an eigenvector for the non-numeraire substitution matrix.

\subsection{Univariate Tariff Reduction Reform}

We now consider the conditions under which a univariate tariff reform, in which the tariff on a single good is reduced, is locally optimal.

Proposition 9 Let the substitution matrix $S_{\pi \pi}\left(\pi^{0}, u^{0}\right)$ be of maximal rank, $n-1$. Then the univariate tariff reform, in which the tariff on good 1 (for example) is reduced, is locally optimal if, and only if, the initial tariff vector satisfies the condition $\tau^{0}=$ $-S_{\rho \rho}\left(\pi^{0}, u^{0}\right)^{-1} S_{\rho 1} t_{1}^{0}$.

Proof. The equality in the Cauchy-Schwarz inequality occurs if, and only if, the vectors are proportional to one another and, in the present context, this means that $S_{\pi \pi}\left(\pi^{0}, u^{0}\right) t^{0}=\kappa e_{i}$ for some scalar $\kappa$. This equality constitutes a set of $n$ linear equations that the vector $t^{0}$ is to satisfy. Since the rank of the substitution matrix is assumed to be $n-1$, one equation (say the $i$ th) may be ignored, leaving $n-1$ equations in $n$ unknowns. Tariff $t_{i}^{0}$ may be arbitrarily chosen and these equations may be solved for the remaining tariffs. For simplicity of notation, and without loss of generality, let $i=1$. Then the equations to solve are $S_{\rho \rho}\left(\pi^{0}, u^{0}\right) \tau^{0}=-S_{\rho 1} t_{1}^{0}$ and the solution is $\tau^{0}=-S_{\rho \rho}\left(\pi^{0}, u^{0}\right)^{-1} S_{\rho 1} t_{1}^{0}$. 
Thus, if the initial tariff vector satisfies these equations then the equality in the CauchySchwarz inequality holds and so $d u^{1}=d u^{S}$. If these equations do not hold, then the strict inequality $\left|t^{0 \prime} S_{\pi \pi}\left(\pi^{0}, u^{0}\right) e_{1}\right|<\left\|t^{0 \prime} S_{\pi \pi}\left(\pi^{0}, u^{0}\right)\right\|$ holds and so $d u^{1}<d u^{S}$. For the case where $i \neq 1$ the argument is exactly the same except that the notation needs amendment. The simplest approach is to re-order goods so that good $i$ becomes the first and then our proof applies. Alternatively, the condition becomes $t_{-i}^{0}=-S_{-i,-i}\left(\pi^{0}, u^{0}\right)^{-1} S_{-i, i} t_{i}^{0}$, where the notation $-i$ denotes all the rows or columns except the $i$ th ones.

Again, just as in the discussion of the local optimality of the proportional tariff reform, this proposition may also be readily extended to the case where reforms are restricted to non-numeraire goods. In the special case of just two goods, with good 1 being the untaxed numeraire, the reduction of the tariff on good 2 (the only tariff) is identical to the proportional tax reform and both are locally optimal. More generally, the above proposition indicates the conditions under which the univariate reform is locally optimal.

\subsection{Comparisons of Reform Directions}

Using the fact that the gradient vector and steepest ascent tariff reform vector are the same except for length and related by equation (3), the welfare changes for the steepest ascent, proportional and univariate tariff reforms may also be expressed as

$$
\begin{aligned}
d u^{S} / d \alpha & =D\left(t^{0}, \delta^{S}\right)=\theta^{-1} \widetilde{\delta}^{S \prime} \widetilde{\delta}^{S} \\
d u^{P} / d \alpha & =D\left(t^{0}, \delta^{P}\right)=-\left(l \theta^{-1} /\left\|t^{0}\right\|\right) \widetilde{\delta}^{S \prime} t^{0} \\
d u^{i} / d \alpha & =D\left(t^{0}, \delta^{i}\right)=-\left(l \theta^{-1}\right) \widetilde{\delta}^{S \prime} e_{i} .
\end{aligned}
$$

These expressions show that the sign of the change in utility depends upon the inner product between the normalized steepest ascent direction vector $\widetilde{\delta}^{S}$ and the direction of the reform in question. For example, the change in utility for the steepest ascent reform is proportional to $\widetilde{\delta}^{S /} \widetilde{\delta}^{S}$, which is always positive. The change in utility for the proportional tariff reduction reform is proportional to $-\widetilde{\delta}^{S \prime} t^{0}$, which is always positive since $-t^{0}$ and $\widetilde{\delta}^{S}$ are at an acute angle to each other (implication of the fact that $d u^{P}>0$ ). Finally, the change in utility for a univariate reduction in the tariff on product $i$ is proportional 
to $-\widetilde{\delta}^{S \prime} e_{i}$. Whether this reform is welfare improving depends on whether $-e_{i}$ and $\widetilde{\delta}^{S}$ are at an acute angle to each other; if good $i$ is a concertina good, then the angle is acute.

These observations provide a geometric interpretation of the directions of reform that will be welfare improving. Figure 4 illustrates various reforms. Any reforms that are at an acute angle with $\widetilde{\delta}^{S}$ will be welfare improving. Conversely, any reforms that are orthogonal to $\widetilde{\delta}^{S}$ or at an obtuse angle to $\widetilde{\delta}^{S}$ will yield zero welfare gains or welfare losses respectively. These reforms have direction vectors pointing along the tangent plane $T T$ or pointing in the half-space to the south-east of TT. Another implication is that the closer a reform vector is to $\widetilde{\delta}^{S}$, the greater will be the welfare gain, for then the inner product with $\widetilde{\delta}^{S}$ will be larger.

Figure 4: (about here)

In this figure, which illustrates one possibility and not a general result, the reform that yields the welfare gain closest to that attained by the steepest ascent reform is the reduction in the tariff on good $1\left(\widetilde{\delta}^{i}\right)$. Next comes the proportional tariff reduction reform $\left(\widetilde{\delta}^{P}\right)$, followed in last place by the reduction in the tariff on good 2 , a reform that yields a welfare loss. The proportional tariff reduction reform yields modest welfare gains since it reduces both tariffs, while the locally optimal reform calls for an increase in the tariff on good 2. The reform reducing the tariff on good 1 alone does much better and its welfare gain is close to that of the steepest ascent reform. The reduction of the tariff on good 2 is a bad choice of policy in this second best framework.

The above comparisons of the welfare consequences of various tariff reforms with the locally optimal steepest ascent tariff reform leads to a general efficiency measure that can be applied to any reform. If $\delta$ is the (normalized) direction of an arbitrarily given tariff reform $d t=\delta d \alpha$ and $\delta^{S}$ is that for the steepest ascent tariff reform, the index of the welfare effectiveness of the reform may be defined as

$$
I(\delta) \equiv \delta^{\prime} \delta^{S} / \delta^{S \prime} \delta^{S}
$$

This index is close to unity if the direction of tariff reform given by $\delta$ is close to $\delta^{S}$, meaning that the angle between them is small. Conversely, if these reform directions are 
orthogonal, the index is zero and the reform does not yield a gain in utility. If the reform direction $\delta$ is at an obtuse angle to $\delta^{S}$ then there will be a welfare loss associated with the reform. This index is used on numerical examples below.

\subsection{Numerical Examples}

In this section, we undertake some calculations of welfare gains from the steepest ascent, proportional and univariate tariff reforms using numerical examples. By undertaking these numerical simulations, we are able to gain some further insights into the welfare effectiveness of these tariff reforms. We begin with a three commodity example and then provide results for a nine commodity case.

\subsubsection{Example with three goods}

In the first example there are three traded goods. The world price, specific tariff and domestic price vectors are:

$$
\begin{aligned}
p & =\left(\begin{array}{lll}
1 & 0.2 & 0.36
\end{array}\right)^{\prime} \\
t^{0} & =\left(\begin{array}{lll}
0 & 0.8 & 0.64
\end{array}\right)^{\prime} \\
\pi^{0} & =\left(\begin{array}{lll}
1 & 1 & 1
\end{array}\right)^{\prime}
\end{aligned}
$$

and the substitution matrix at the initial equilibrium is assumed to be

$$
S_{\pi \pi}=\left[\begin{array}{ccc}
-1 & .55 & .45 \\
.55 & -1.1 & .55 \\
.45 & .55 & -1
\end{array}\right]
$$

The steepest ascent tariff direction is given by the gradient vector $\nabla U\left(t^{0}\right)$, which, assuming that $p^{\prime} S_{\pi u}=1$, is

$$
\delta^{S}=\left[\begin{array}{c}
0.73 \\
-0.53 \\
-0.20
\end{array}\right]
$$


This reform calls for an increase in the tariff on the first good and reductions in the tariffs on the other two goods. If this tariff reform is undertaken, with the reform length normalized to be unity, the change in utility is $d u^{S}=0.921$.

Now consider the steepest ascent tariff reform if it is further required that the reform only involves non-numeraire goods. In this case, the first element of the gradient vector is ignored and the reform is set equal to the second and third elements. This reform calls for reductions in tariffs on goods two and three, leaving the tariff on good 1 at zero. If this tariff reform is undertaken, with the reform length normalized to be unity, the change in utility is $d u^{S}=0.565$. Although this might seem puzzling at first, we have effectively lost one policy instrument and are now in a second best, piecemeal policy situation. Consequently, the welfare increase is less than if we had the full set of instruments at our disposal. $^{18}$

Any other tariff reform (of the same length) must give a lower utility gain and so is locally suboptimal. ${ }^{19}$ The utility gains for several other reforms of equal length were calculated. These were (a) proportional reductions in all non-numeraire tariffs, (b) reductions of the tariffs on each non-numeraire good taken one at a time and (c) a reduction of the tariffs on all non-numeraire goods (goods 2 and 3). The welfare gains for each reform were expressed as a proportion of the welfare gain for the steepest ascent tariff reform. This exercise was undertaken twice - once where the reforms were restricted to non-numeraire goods only and then when the reforms applied to all goods. The resulting indices of welfare gain relative to the maximum gain that is feasible (given by the steepest ascent reform), given by (23), are presented in Table 1 .

Looking at the results for the gains relative to those for the steepest ascent tariff reform applied to non-numeraire goods only, we see that the proportional reform works very well, yielding $95 \%$ of the potential (steepest ascent) gain. This is because the initial conditions call for a reduction in the tariff rates on both non-numeraire goods. ${ }^{20}$ The

\footnotetext{
${ }^{18}$ This example accordingly provides a concrete illustration of Proposition 4, which states that there is a welfare loss associated with a tariff reform restricted to non-numeraire goods compared to a reform of the tariff rates of all goods. The welfare loss arises because of the restriction of reforms to a common sphere. Without this restriction, there would be no welfare loss, of course.

${ }^{19}$ We must restrict all reforms to be of the same length to permit a valid comparison of these reforms.

${ }^{20}$ In other examples that call for increases in tariffs on some goods, the proportional reduction reform
} 
Table 1: Indices of Welfare Gain from Various Tariff Reforms: Example with Three Goods

\section{Goods Subject to Reform}

$\begin{array}{ccc}\text { Tariff Reform } & \text { Non-numeraire } & \text { All goods } \\ \text { Steepest Ascent } & 1.0 & 1.0 \\ \text { Proportional } & .95 & .58 \\ \text { Good 2 } & .94 & .57 \\ \text { Good 3 } & .35 & .22 \\ \text { Goods 2-3 } & .91 & .56\end{array}$

initial equilibrium is such that good 2 is a concertina good - it has the highest ad valorem tariff rate (expressed in domestic prices) and good 2 is a net substitute for the other goods $\left(S_{2 j}>0\right.$ for $\left.j \neq 2\right)$. Hence, the reduction of the tariff on good 2 yields a large welfare improvement of $d u^{2}=0.94$ and, indeed, this reform performs almost as well as the proportional reduction reform. Good 3 is not a concertina good, but a reduction of its tariff nevertheless yields a more modest welfare improvement of $d u^{3}=0.35$. The reduction of tariffs on both non-numeraire goods (non-proportionally) is not as effective as the reduction of the tariff of good 3 alone, which is where the biggest distortion lies.

When comparisons are made with the steepest ascent reform applied to all goods, it is seen that the other reforms are now much less impressive. While the welfare gains from each of these reforms is the same as when all goods are subject to the reforms (recall that the tariff on the numeraire good is zero initially), the gain from the steepest ascent reform is much bigger, as explained further above. This difference raises an important issue regarding the choice of context in which to undertake a comparison of piecemeal reforms.

\subsubsection{Example with nine goods}

Our second illustrative example is for a model that has $n=9$ goods. ${ }^{21}$ Table 2 provides the results for the indices of welfare gains, relative to the steepest ascent reform, arising

performs less well and, sometimes, poorly, as might be expected.

${ }^{21}$ Details of the initial tariffs, prices and substitution matrix used in this example are available from the authors. 
from the application of the various tariff reforms to the tariffs of non-numeraire goods in this model.

Table 2: Indices of Welfare Gain from Various Tariff Reforms: Example with Nine Goods

$\begin{array}{cc}\begin{array}{c}\text { Goods Subject } \\ \text { Non-numeraire }\end{array} & \begin{array}{c}\text { to Reform } \\ \text { All goods }\end{array} \\ 1.0 & 1.0 \\ .289 & .287 \\ .263 & .260 \\ .159 & .158 \\ .095 & .094 \\ .179 & .177 \\ .213 & .211 \\ .015 & .014 \\ .114 & .113 \\ -.898 & -.889 \\ .049 & .049\end{array}$

The results in Table 2 starkly illustrate the observation that there can be wide variations in the effectiveness of the proportional and univariate (single good) tariff reforms relative to the (locally optimal) steepest ascent reform even when the reforms are restricted to tariffs of non-numeraire goods. ${ }^{22}$ In this example, the proportional tariff reform is only about $29 \%$ effective in raising welfare, despite the fact that the gradient vector calls for a reduction in the tariff of every good except one. The distortion on this good (good 9 ) is very large, however. Moreover, good 9 has the lowest tariff and is strongly netsubstitutable with every good, except the numeraire. Consequently, it is a concertina good in reverse - welfare gains arise from raising its tariff, not reducing it as the proportional reform requires. This reduces the effectiveness of the proportional reduction tariff reform.

The univariate tariff reforms vary substantially in their effectiveness at raising welfare. For those univariate reforms that raise welfare, the indices of welfare gain vary from a high of 0.26 when the tariff on good 2 is reduced down to a gain of just 0.01 when the tariff on

\footnotetext{
${ }^{22}$ Many other examples, with different numbers of goods and substitution matrices, provided similar support for this observation.
} 
good 7 is reduced. Of course, the reduction of the tariff on good 9, which is a concertina good in reverse, yields a large reduction in the index of welfare gain. Conversely, if the tariff on this good were to be raised, the index of welfare gain would be large.

As a final observation on Table 2, we note that the efficiencies of the various reforms relative to the steepest ascent reform applied to all goods are only marginally less than their efficiencies relative to the steepest ascent reform applied to only non-numeraire goods. This result for the 9-good example is in contrast with the result noted above for the 3-good example. This difference in results suggests that the welfare loss associated with restricting the steepest ascent reform to non-numeraire goods is smaller, the larger the number of goods; the restriction on the single numeraire good takes lower importance due to the larger number of goods whose tariffs are reformed.

Before we conclude, we should note that while specific examples cannot provide general conclusions, they do provide valuable illustrations of the relative merits of alternative tariff reforms in a range of contexts. Our examples illustrate several main observations. First, the restriction of reforms (of the same length) to non-numeraire goods only can result in a substantial loss of welfare gain compared to allowing all tariffs to be reformed. Second, the effectiveness of different reforms depends crucially upon the initial distortions captured by the tariff rates and the substitution matrix. Finally, there can be substantial variation in the welfare effectiveness of the various reforms such as the proportional and univariate reforms.

\section{A Different Application: Market Access and SATR}

Thus far, we have been concerned with the welfare implications of the steepest ascent tariff reform. We now turn to the question of how the steepest ascent tariff reform relates to the issue of market access, as discussed by Ju and Krishna (2000) and Anderson and Neary (2006). This topic is pertinent for two main reasons. First, the relationship, particularly the potential conflict, between the objectives of increasing market access and of increasing consumer welfare is interesting in its own right and an important issue in international trade policy. What are the effects on welfare of tariff reforms designed to increase market 
access? Conversely, what is the effect upon market access of reforms that raise consumer welfare? Are these objectives in conflict or can they be attained by the same reform? Second, the issue of market access provides an illustration that our concept of a steepest ascent tariff reform may be applied to objectives other than welfare. Accordingly, we derive below a steepest ascent tariff reform that locally maximizes the increase in market access.

Market access is defined as $M=q^{\prime} m(\pi, u)$, where $q$ is the non-numeraire world price vector and $m(\pi, u)$ is the vector of import functions of non-numeraire goods. It is assumed that all goods that are not imported have zero tariffs and are aggregated into the numeraire good, which is therefore a composite commodity. As previously, $\tau$ is the tariff vector for non-numeraire goods (the tariff on the numeraire composite good being zero) and $\rho=q+\tau$ is the domestic price vector for non-numeraire goods. Under these definitions, market access, $M$, is the value of imports at world prices. The change in market access as a result of a tariff change is

$$
d M=\left(q+M_{b} \tau\right)^{\prime} \Sigma^{\prime} d \tau
$$

where $M_{b}=q^{\prime} m_{I} /\left(1-\tau^{\prime} m_{I}\right)$ is the marginal propensity to spend on importable commodities and $m_{I} \equiv\left(-S_{\rho u} / S_{u}\right)$ is the extra consumption of imports arising from an extra dollar of income.

If we use the steepest ascent tariff reform of tariffs on non-numeraire goods, $d \tau=$ $\lambda \Sigma \tau d \alpha$, then the change in market access is

$$
\begin{aligned}
\lambda^{-1} d M / d \alpha & =\left(q+M_{b} \tau\right)^{\prime} \Sigma^{\prime} \Sigma \tau \\
& =q^{\prime} \Sigma^{\prime} \Sigma \tau+M_{b} \tau^{\prime} \Sigma^{\prime} \Sigma \tau
\end{aligned}
$$

This may be further expressed in terms of measures of the levels of prices and tariffs, the dispersion of tariffs and of a measure of the correlation between prices and tariffs as

$$
\lambda^{-1} d M / d \alpha=C+s \bar{q} \bar{\tau}+M_{b}\left(V+s \bar{\tau}^{2}\right)
$$


where $C \equiv(q-\iota \bar{q})^{\prime} \Sigma^{\prime} \Sigma(\tau-\iota \bar{\tau})$ is defined as the generalized covariance between $q$ and $\tau$ and the generalized mean of world prices is defined as $\bar{q} \equiv \iota^{\prime} \Sigma^{\prime} \Sigma q / s$.

This equation provides an expression for the change in market access that arises from application of the steepest ascent tariff reform, which provides the optimal tariff reform (of tariffs of non-numeraire goods) when utility is the objective of the reform. The expression is fairly complex and ambiguous in sign, but depends on several summary measures of the initial equilibrium. The greater is the generalized covariance between $q$ and $\tau$, the greater is the change in market access. Similarly, the larger is the generalized variance, $V$, the greater will be the change in market access.

Now consider a tariff reform that is steepest ascent for market access, i.e. a reform that will yield the largest possible increase the world price value of imports. The gradient of $M$ with respect to tariffs is, from above, $g=\Sigma\left(q+M_{b} \tau\right)$ and so the steepest ascent tariff reform for market access is $\delta^{M}=\Sigma\left(q+M_{b} \tau\right)$. By construction, this tariff reform must raise market access unless the gradient vanishes $(g=0)$. How is utility affected if this steepest ascent tariff reform that is locally optimal for market reform is enacted? The change in utility is given by

$$
\begin{aligned}
H d u / d \alpha & =\tau^{\prime} \Sigma^{\prime} d \tau \\
& =\tau^{\prime} \Sigma^{\prime} \Sigma\left(q+M_{b} \tau\right) \\
& =\left(q+M_{b} \tau\right)^{\prime} \Sigma^{\prime} \Sigma \tau
\end{aligned}
$$

where $H=-S_{u}\left(1-\tau^{\prime} m_{I}\right)>0$ (due to the Hatta normality condition).

What is remarkable about this expression (29) for the effect of the market access based steepest ascent tariff reform upon utility is that it is the same as the expression (27) for the effect of a utility based steepest ascent tariff reform upon market access, apart from positive scalar multipliers. That is, $\lambda^{-1} d M / d \alpha=H d u / d \alpha=\left(q+M_{b} \tau\right)^{\prime} \Sigma^{\prime} \Sigma$. Thus, we have:

Proposition 10 The effect of a steepest ascent tariff reform directed at utility upon market access is precisely the same as the effect of a steepest ascent tariff reform directed at market access upon utility (apart from positive scalar multipliers). Thus, the steepest 
ascent tariff reform directed at market access has a positive effect upon utility if, and only if, the steepest ascent tariff reform directed at utility has a positive effect upon market access.

This appears to be an interesting "duality" result between welfare and market access effects of (differently based) steepest ascent tariff reforms. Clearly, the implications of this result for the market access and welfare literature are needed to be developed more fully. Here we only note this result in order to highlight that our proposed method can bring new insights to the policy reform literature.

\section{Conclusions}

The steepest ascent tariff reform concept proposed in this paper provides a standard or benchmark by which other reforms may be compared in terms of their effectiveness in generating welfare gains. Tariff reforms can, at best, attain the welfare gain that is achieved by the steepest ascent tariff reform, since it is locally optimal. Hitherto, the tariff reform literature has been focused on establishing reforms that yield a welfare improvement and has therefore been concerned only with the sign of the welfare effect. The motivation for the present paper has been two-fold. The first has been to characterize and establish the nature of the tariff reform that is locally optimal and this has yielded our steepest ascent tariff reform. The second motivation was to provide a benchmark tariff reform with which all other existing and potential reforms can be compared and to provide a means of determining their relative efficiency in yielding welfare improvements. The steepest ascent tariff reform also provides this outcome. In other words, our paper provides a different focus from that which has characterized the literature - one which is upon the size of the welfare effects rather than simply the sign.

We have established several properties of the steepest ascent tariff reform, characterized the sources of potential gains from tariff reforms and compared the welfare effectiveness of the proportional and univariate tariff reforms. We have also applied it to the issue of how tariff reforms affect market access.

Not surprisingly, application of the steepest ascent tariff reform formula to an actual 
economy requires knowledge of the net substitution matrix at the initial equilibrium as well as the initial tariff rates and is therefore demanding in terms of information requirements. While the econometric estimation of the substitution matrix for a reasonably disaggregated set of commodities is not feasible, there are many computable general equilibrium models for various countries that have very detailed information about the production and consumption sectors that enable the computation of this net substitution matrix. ${ }^{23}$ Accordingly, the calculation of the steepest ascent tariff reforms for such economies is already feasible for many countries thus making the concept of practical policy relevance as well as being a valuable theoretical benchmark for various reform proposals.

While our steepest ascent tariff reform definition and the comparison between various reforms were made on the basis of reforms of equal length, extensions of the concept to alternative constraints sets can be contemplated. One possibility is to include costs of making tariff reforms into the model and to restrict the reform vectors to be of equal cost. Although we have followed the international trade literature in which revenue implication of reforms are typically not of primary concern, another potentially important possibility is to require that feasible tariff reforms have the same tariff revenue implications.

Finally, it is noteworthy that the concept of a steepest ascent or locally optimal policy reform is not restricted to tariff reform but may be applied to any set of policy instruments. It could be applied, for example, to quotas on trade. Similarly it could be applied to the reform of domestic taxes. Also, the concept does not have to be restricted to measuring the gains in utility of a reform but can be applied to any objective function. As an example, in this paper we briefly considered a steepest ascent tariff reform where the objective function was a measure of market access. An alternative objective function might be the value of production in some domestic industry or in the income of a factor of production, to give just two additional examples. In short, the concept is applicable whenever we wish to determine the best possible piecemeal reform in terms of some objective function or to compare the effectiveness of alternative policy reforms in attaining that objective.

\footnotetext{
${ }^{23}$ A similar issue could be raised with respect to the Anderson and Neary (1996) index of trade restrictiveness. However, and as it has been shown by the work of Anderson and Neary (2005) and by recent work of Kee et al. (2006), such indexes can indeed be measured with relative ease.
} 


\section{Appendix: Choice of Policy Instrument}

In the paper, we have assumed that the policy instrument at the disposal of the government comprises the specific tariff rates, as is common in the literature. The tariff reforms consist of changes in the specific tariff rate vector. The alternative is to assume that the policy reform is expressed in terms of changes in (a) ad valorem tariff rates, (b) tariff factor rates or (c) domestic prices. In this appendix, we show how the steepest ascent concept may be applied to each of these sets of policy instruments.

First, we consider the steepest ascent reform of domestic prices. The model may be expressed as

$$
p^{\top} S_{\pi}(\pi, u)=b
$$

which makes it clear that the resulting indirect utility function $W(\pi ; p, b)$ is homogeneous of degree zero in $(p, b)$ and homogeneous of degree zero in $\pi$. A little reflection, based on the fact that $\pi^{0}=p+t^{0}$ is additive in $t^{0}$, indicates that the previous development of a steepest ascent tariff reform expressed in terms of $U(t)$ may be directly applied to a steepest ascent reform of domestic prices expressed in terms of $W(\pi)$, subsuming the (fixed) $p$ and $b$ variables. Thus, the steepest ascent reform of domestic prices is

$$
\delta^{\pi S}=\delta^{S}=\lambda S_{\pi \pi}\left(\pi^{0}, u^{0}\right) t^{0}, \quad \lambda>0
$$

and the resulting change in utility is

$$
D\left(\pi^{0}, \delta^{\pi S}\right)=\left(\lambda / H^{2}\right) t^{0 \prime} S_{\pi \pi}\left(\pi^{0}, u^{0}\right) S_{\pi \pi}\left(\pi^{0}, u^{0}\right) t^{0}
$$

Having established the steepest ascent reform of domestic prices, we can now consider the nature of reforms of policy instruments that determine the domestic prices.

Second, consider specific tariffs (already dealt with in the text of the paper). We write domestic prices in terms of specific tariffs as $\pi^{0}=f\left(t^{0}\right) \equiv p+t^{0}$ and note that $\nabla f\left(t^{0}\right) \equiv I$, the identity matrix. Thus, to get the steepest ascent specific tariffs we write $U(t) \equiv$ $W(f(t))$ and apply the steepest ascent method to obtain $\nabla U(t) \equiv \nabla f(t) \nabla W(f(t))=$ $\nabla W(f(t))$. This just confirms that the steepest ascent directions for $t$ and for $\pi$ are the 
same.

Third, consider ad valorem tariffs given by $\tau_{i}=t_{i} / p_{i}$ for $i=1,2, \ldots, n$. We write domestic prices in terms of ad valorem tariffs as $\pi^{0}=g\left(\tau^{0}\right) \equiv p \cdot\left(1+\tau^{0}\right)$, where $\cdot$ denotes "horizontal" multiplication, and note that $\nabla f\left(t^{0}\right) \equiv P$, the matrix diagonalization of the world price vector, $p$. Thus, to get the steepest ascent ad valorem tariffs we write $U(\tau) \equiv$ $W(g(\tau))$ and apply the steepest ascent method to obtain $\nabla U(\tau) \equiv \nabla g(\tau) \nabla W(g(\tau))=$ $P \nabla W(g(\tau))$. Accordingly, the steepest ascent ad valorem tariff reform is given by

$$
\begin{aligned}
\delta^{\tau S} & =\lambda P S_{\pi \pi}\left(\pi^{0}, u^{0}\right) t^{0} \\
& =\lambda P S_{\pi \pi}\left(\pi^{0}, u^{0}\right) P \tau^{0} \\
& =\lambda \widehat{\Sigma} \tau^{0}, \quad \lambda>0,
\end{aligned}
$$

where $\lambda=\theta / p^{\prime} S_{\pi u}\left(\pi^{0}, u^{0}\right)>0$ and $\widehat{\Sigma} \equiv P S_{\pi \pi}\left(\pi^{0}, u^{0}\right) P$ is a negative semidefinite matrix. The first line in these expressions shows that the sign structure the ad valorem tariff direction is the same as for a specific tariff, but that the direction itself is different because of the multiplication of the rows by the respective world prices required by the formulae. The resulting change in utility is

$$
D\left(\pi^{0}, \delta^{\tau S}\right)=\left(\lambda / H^{2}\right) \tau^{0} \widehat{\Sigma} \widehat{\Sigma} \tau^{0}>0
$$

Finally, for completeness, we present results for tariff factors defined as $\sigma_{i}=1+\tau_{i}$ for $i=1,2, \ldots, n$. Now we can write $t=P(1-\sigma)$ and so the steepest ascent direction for tariff factors is

$$
\begin{aligned}
\delta^{\sigma S} & =\lambda P S_{\pi \pi}\left(\pi^{0}, u^{0}\right) t^{0} \\
& =\lambda P S_{\pi \pi}\left(\pi^{0}, u^{0}\right) P\left(1-\sigma^{0}\right) \\
& =\lambda \widehat{\Sigma}\left(1-\sigma^{0}\right), \quad \lambda>0,
\end{aligned}
$$

and the resulting change in utility is

$$
D\left(\pi^{0}, \delta^{\sigma S}\right)=\left(\lambda / H^{2}\right)\left(1-\sigma^{0}\right)^{\prime} \widehat{\Sigma} \widehat{\Sigma}\left(1-\sigma^{0}\right)>0
$$




\section{References}

[1] Abe, K., 1992, Tariff reform in a small open economy with public production, International Economic Review, 33, 209-222.

[2] Anderson, J.E., and J.P. Neary, 1992, Trade reform with quotas, partial rent retention and tariffs, Econometrica, 60, 57-76.

[3] — and — 1996, A new approach for evaluating trade policies, Review of Economic Studies, 63, 107-125.

[4] — and — , 2005, Measuring the Restrictiveness of International Trade Policy, MIT Press.

[5] — and — , 2006, Welfare versus market access: The implications of tariff structure for tariff reform, Journal of International Economics, forthcoming.

[6] Apostol, T.M. (1957), Mathematical Analysis, Addison-Wesley Publishing Company, Reading, Mass.

[7] Bhatti, M.A., 2000, Practical Optimization Methods, Springer-Verlag, New York.

[8] Diewert, W.E., 1978, Optimal tax perturbations, Journal of Public Economics, 10, 139-177.

[9] Diewert, W., A. Turunen-Red, and A.D. Woodland, 1989, Productivity and Paretoimproving changes in taxes and tariffs, Review of Economic Studies, 56, 199-215.

[10] Diewert, W.E., Turunen-Red, A.H. and A.D. Woodland, 1991, Tariff reform in a small open, multi-household economy with domestic distortions, International Economic Review, 32-4, 937-957.

[11] Fare, R. and D. Primont, 2006, Directional duality theory, Economic Theory, 28, 1-9.

[12] Fukushima, T., 1979, Tariff structure, nontraded goods and theory of piecemeal policy recommendations, International Economic Review, 20-2, 427-435.

[13] Hatta, T., 1977a, A recommendation for a better tariff structure, Econometrica, 45-8, 1859-1869.

[14] — 1977b, A theory of piecemeal policy recommendations, Review of Economic Studies, 44, 1-21.

[15] Ju, J. and K. Krishna, 2000, Welfare and market access effects of piecemeal tariff reform, Journal of International Economics, 51-2, 305-316.

[16] Kee, H.L., A. Nicita , and M. Olarreaga, 2006, Estimating trade restrictiveness indices, CEPR DP 5576, London.

[17] Lloyd, P.J., 1974, A more general theory of price distortions in open economies, Journal of International Economics, 4, 365-386. 
[18] Luenberger, D.G., 1984, Linear and Nonlinear Programming, 2nd edition, AddisonWesley, Reading, Mass.

[19] Meade, J.E., 1955, Trade and Welfare, Oxford University Press, Oxford.

[20] Neary, P.J., 1995, Trade liberalisation and shadow prices in the presence of tariffs and quotas, International Economic Review, 36-3, 531-554.

[21] Press, W.H., Flannery, B.P., Teukolsky, S.A. and W.T. Vetterling, 1986, Numerical Recipes, Cambridge University Press, Cambridge.

[22] Tirole, J. and R. Guesnerie, 1981, Tax reform from the gradient projection viewpoint, Journal of Public Economics, 15, 275-293

[23] Turunen-Red, A.H. and A.D. Woodland, 1992, Strict Pareto improving reforms of tariffs, Econometrica, 59, 1127-1152..

[24] — and — 2001, The anatomy of multilateral trade policy reform, in Lahiri, S. (Editor), Regionalism and Globalization: Theory and Practice, Routledge Contemporary Economic Policy Issues Series.

[25] Weymark, J.A., 1981, Undominated directions of tax reform, Journal of Public Economics, 16, 343-369. 


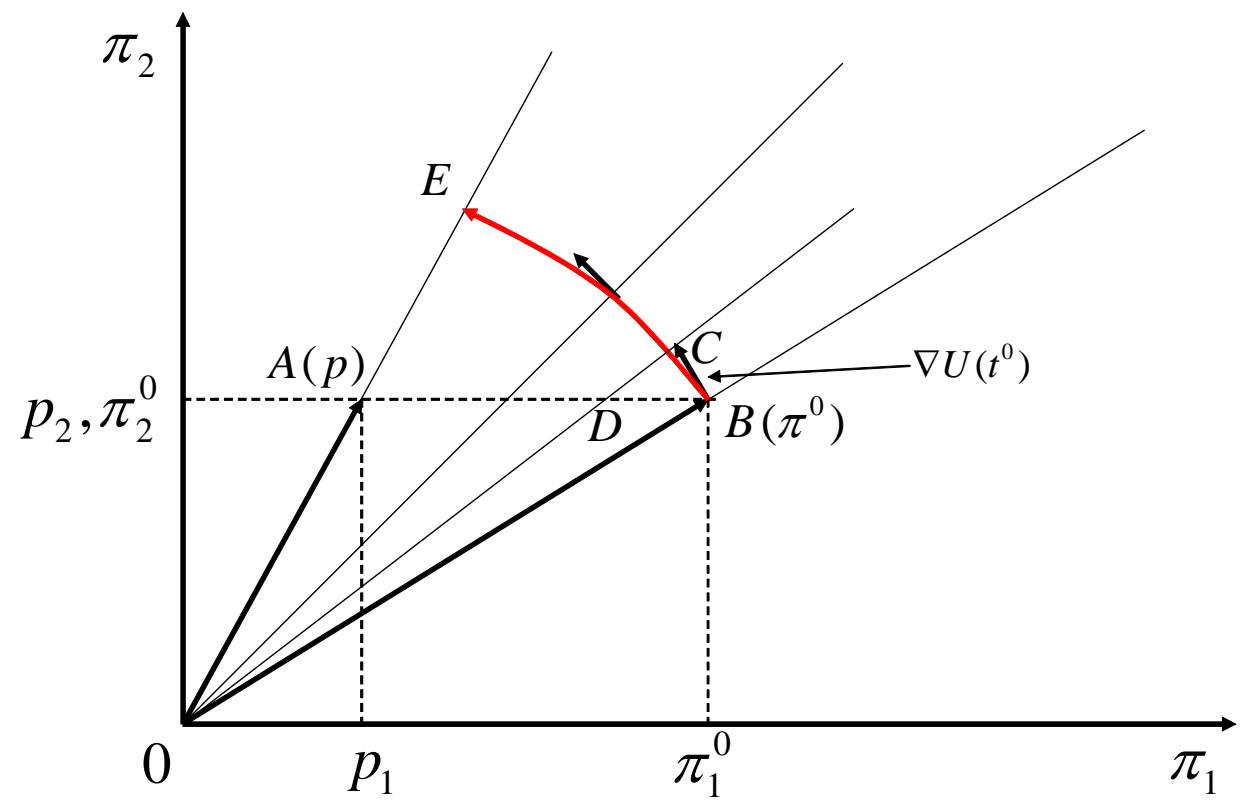

Figure 1: Steepest Ascent Tariff Reform with Two Goods

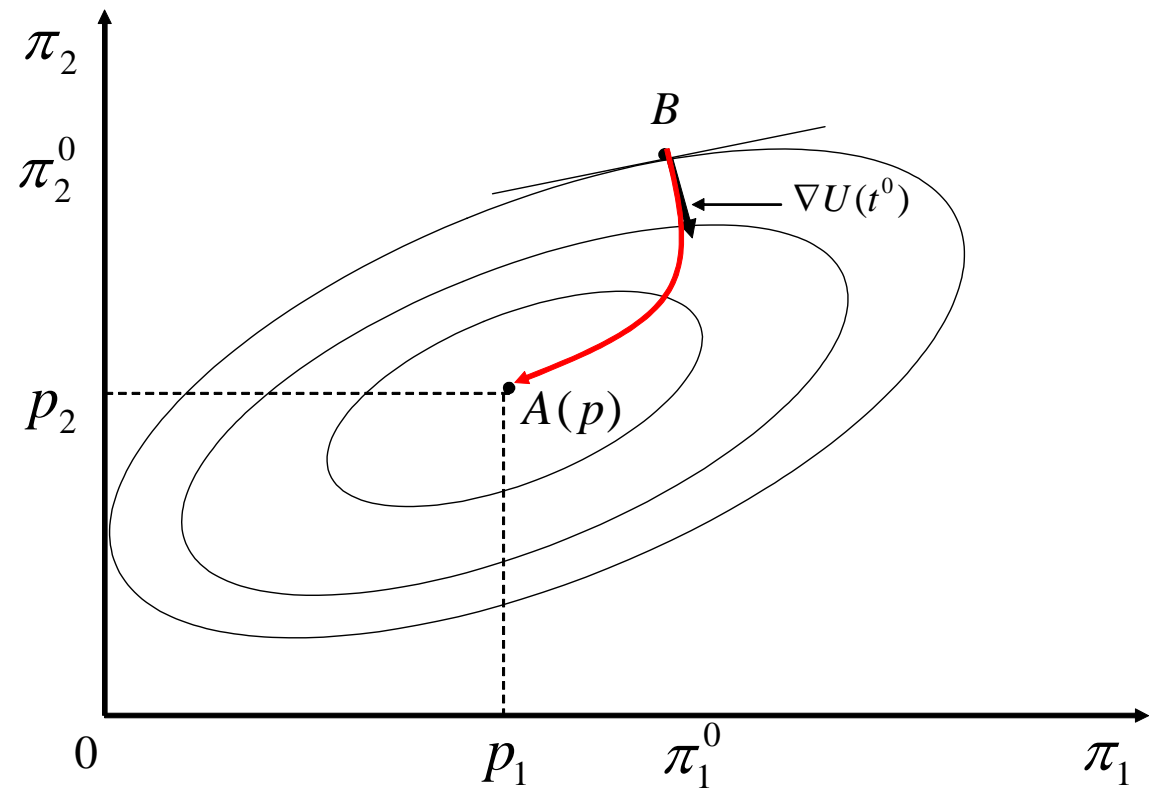

Figure 2: Steepest Ascent Tariff Reform and Continuous Reform Path 


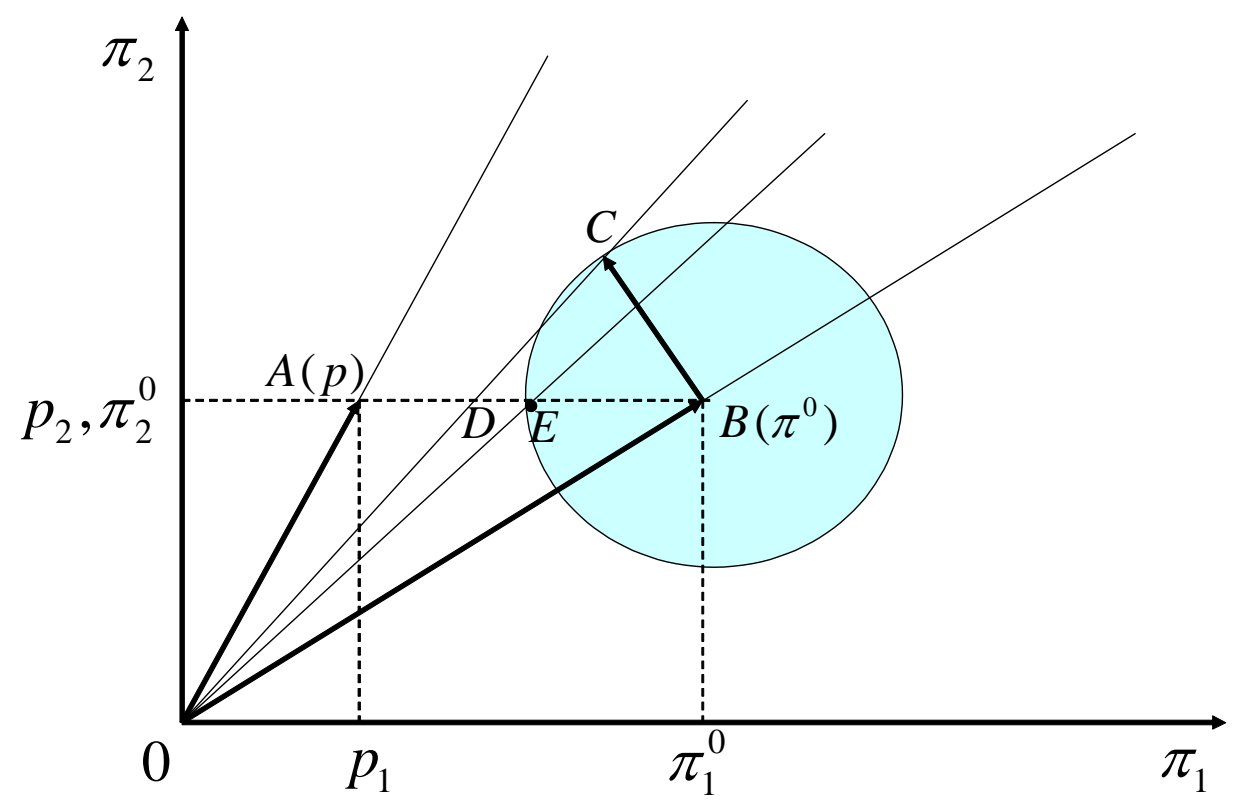

Figure 3: Complete and Restricted Tariff Reforms

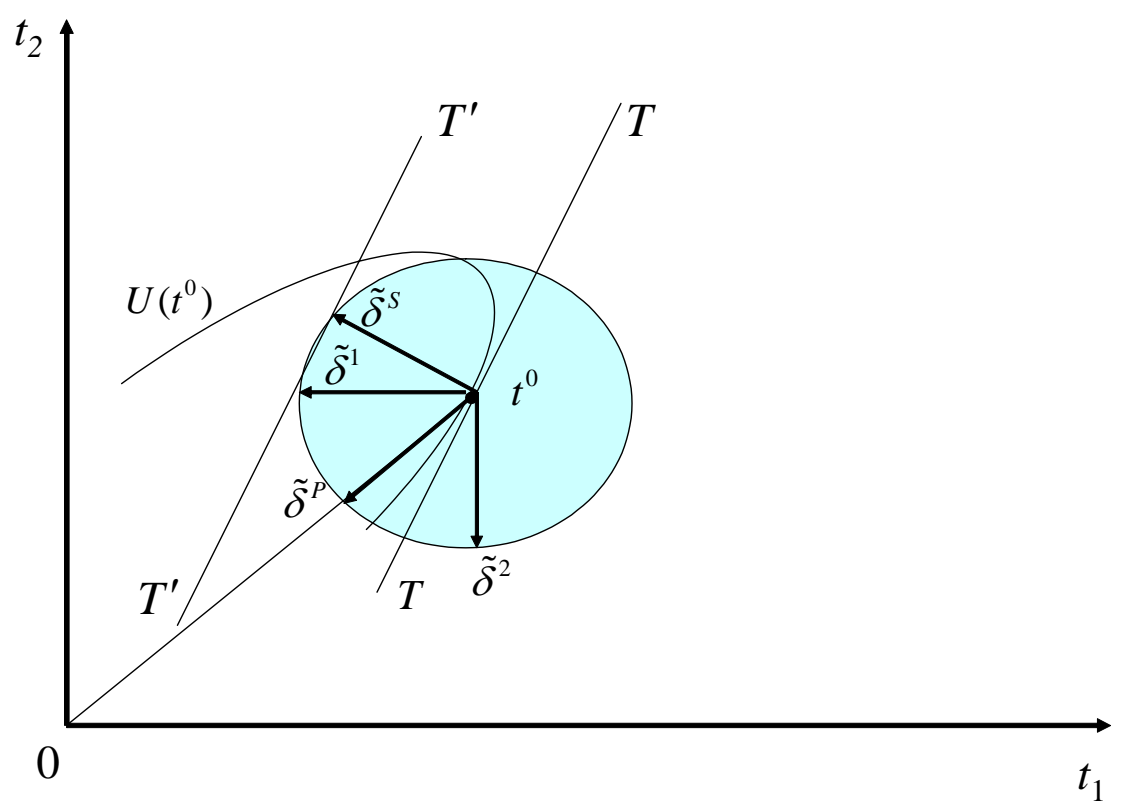

Figure 4: Directions of Tariff Reform and Welfare Gains 